\title{
The Role of Deubiquitinases in Virus Replication and Host Innate Immune Response
}

\author{
Qinglin Zhang ${ }^{1}$, Qizhen Jia ${ }^{1}$, Wenying Gao ${ }^{2 *}$ and Wenyan Zhang ${ }^{2 *}$ \\ ${ }^{1}$ College of Life Sciences of Jilin University, Changchun, China, ${ }^{2}$ Center for Pathogen Biology and Infectious Diseases, \\ Institute of Virology and AIDS Research, Key Laboratory of Organ Regeneration and Transplantation of the Ministry \\ of Education, The First Hospital of Jilin University, Changchun, China
}

As a critical post-translational modification, ubiquitination is known to affect almost all the cellular processes including immunity, signaling pathways, cell death, cancer development, and viral infection by controlling protein stability. Deubiquitinases (DUBs) cleave ubiquitin from proteins and reverse the process of ubiquitination. Thus, DUBs play an important role in the deubiquitination process and serve as therapeutic targets for various diseases. DUBs are found in eukaryotes, bacteria, and viruses and influence various biological processes. Here, we summarize recent findings on the function of DUBs in modulating viral infection, the mechanism by which viral DUBs regulate host innate immune response, and highlight those DUBs that have recently been discovered as antiviral therapeutic targets.

Fei Guo,

$\mathrm{MOH}$ Key Laboratory of Systems Biology of Pathogens, Institute of Pathogen Biology, Chinese Academy of Medical Sciences and Peking Union Medical College,

China

Yong-Hui Zheng, Michigan State University, United States

*Correspondence: Wenying Gao gaowenying@jlu.edu.cn Wenyan Zhang

zhangwenyan@jlu.edu.cn

Specialty section:

This article was submitted to Virology,

a section of the journal

Frontiers in Microbiology

Received: 20 December 2021

Accepted: 12 January 2022

Published: 24 February 2022

Citation:

Zhang $Q$, Jia $Q$, Gao W and

Zhang W (2022) The Role of Deubiquitinases in Virus Replication and Host Innate Immune Response.

Front. Microbiol. 13:839624.

doi: 10.3389/fmicb.2022.839624

\section{INTRODUCTION}

Post-translational modifications (PTMs) play an important role in altering proteins without changing the nucleotide sequence of the organism's DNA or RNA, thus enhancing their response and adaptation to complex environmental variations. PTMS includes methylation, acetylation, phosphorylation, hydroxylation, and ubiquitination (Deribe et al., 2010). Among them, ubiquitination and deubiquitination significantly regulate various cellular processes in eukaryotes, such as signals transduction, protein trafficking, cell motility, transcription, apoptosis, cancer development (Yang et al., 2013; Seo et al., 2018; Tang et al., 2018; Mennerich et al., 2019; Jin et al., 2020; Li et al., 2021). Moreover, the ubiquitination and deubiquitination also exert diverse functions in archaea, bacteria, and viruses (Fuchs et al., 2018; Hermanns and Hofmann, 2019; Wu et al., 2020). The process of ubiquitination involves the conjugation of ubiquitin (Ub) or Ub-like modifiers (Ubl) [for example, the small ubiquitin-like modifier (SUMO), the ubiquitin-like protein (NEDD8), and IFN-induced 15-kd protein (ISG15)] to substrate proteins by three types of enzymes, including E1 ubiquitin-activating enzyme, E2 ubiquitin-conjugating enzyme, an E3 ubiquitin-protein ligase, and the sequential cascades of E1-E2-E3 enzymes have been well studied (Deribe et al., 2010; Zheng and Shabek, 2017; Hu et al., 2020). The important molecule ubiquitin contains seven lysine residues (K6, $\mathrm{K} 11, \mathrm{~K} 27, \mathrm{~K} 29, \mathrm{~K} 33$, K48, and K63) and an $\mathrm{N}$-terminus methionine (M1) serving as ubiquitination sites, which result in various polyubiquitin chain linkage types. "Ubiquitin code" is comprised by the architecture of polyubiquitin chain linkage-type, the number of modified sites, the length of the added ubiquitin molecules, and dictates the fate of the substrates (Komander and Rape, 2012). For example, the K48-linked polyubiquitin chain often leads to proteasome degradation of the protein substrate, whereas K63-linked polyubiquitin mainly involves non-degradative roles such as innate immunity or intracellular trafficking of modified proteins (Oshiumi et al., 2013; Song et al., 2016; 
Okamoto et al., 2017). The conjugation of ubiquitin is reversible since deubiquitinases (DUBs) can cleave peptide or isopeptide bonds between ubiquitin and substrate protein or conjoined ubiquitin molecules. "Ubiquitin code" also dictates a wide variety of distinct DUBs activities and preferences, which has been wellreviewed (Clague et al., 2019).

The study of molecular pathways of deubiquitination was initiated in the 1990s and then further investigated and elucidated (Tobias and Varshavsky, 1991; Baker et al., 1992; Papa and Hochstrasser, 1993; Wilkinson, 1997). DUBs are key effectors of the removal of ubiquitin, which reverses the fate of the modified proteins as well as the following molecular and cellular functions of the proteins (Clague et al., 2013; Kategaya et al., 2017; Clague et al., 2019). DUBs have nearly 100 family members, which are classified into seven families, ubiquitin-specific proteases (USPs), ovarian tumor proteases (OTUs), ubiquitin carboxyl-terminal hydrolases (UCHs), Ataxin-3 like proteins (Josephins), MIUcontaining new DUB family (MIUDY), zinc-finger ubiquitin protease 1 (ZUB/ZUFSP), and Jab/MPN domain-associated metalloisopeptidases (JAMMs) (Hermanns and Hofmann, 2019). Each possesses unique cleavage specificity owing to its structural characteristics (Mevissen and Komander, 2017).

The protein levels of individual DUB and their intracellular localization are important for DUBs function in the cellular process. The estimated copy number of DUBs ranges from the low hundreds (limit of detection) to hundreds of thousands per cell. A systemic subcellular localization screen by GFP (Green fluorescent protein)-tagged DUBs in HeLa cells, combined with individual studies, showed that DUBs distribute in a variety of defined structures, such as the nucleolus (USP36 and USP39), plasma membrane (USP6 and JOSD1), microtubule [USP21 and CYLD (cylindromatosis)], Golgi (USP33V3 and USP32) (reviewed in Clague et al., 2019). DUBs are associated with almost all biological functions and diseases. For example, USP14, CYLD, and UCHL1 regulate cardiac hypertrophy by the different mechanism (Wang et al., 2015; Liu et al., 2016; Bi et al., 2020; Qi et al., 2020). Some DUBs regulate tumorigenesis and migration by their intrinsic oncogenic or tumor suppressor activities (UCHL1 and CYLD), or by controlling key epigenetic changes that affect cancer development (USP22), or by affecting the protein levels and/or activities of various cancer-related proteins (USP7 and USP28) (Sacco et al., 2010; Nicholson and Suresh Kumar, 2011; Wang and Dent, 2014; Harrigan et al., 2018; Xiao et al., 2019). In addition, DUBs have also been reported to function in interferon (IFN) antiviral signaling, dependent or independent of their deubiquitinase activity (Wang L. et al., 2013; Zhong et al., 2013; Fan et al., 2014; Pauli et al., 2014; Zhang et al., 2015; Gu et al., 2017; Qian et al., 2018; Liu et al., 2020).

Virus infection induces a host immune response, and leads to multiple serious diseases, including fever, chronic hepatitis, acquired immunodeficiency syndrome (AIDS), and cervical cancer (Tanuma et al., 2016; De Nola et al., 2019; Gallardo et al., 2019; Thomas, 2019). Furthermore, COVID-19 caused by SARS coronavirus 2 (SARS-CoV-2) has resulted in over 12,340,000 cases and 2,710,000 deaths worldwide until the end of March 2021 (Yamamoto et al., 2020). Therefore, investigations have focused on the molecular mechanisms that regulate or mediate virus replication (García et al., 2017; Kumar et al., 2018; Luo et al., 2018; Zhu et al., 2020). DUBs are known to participate in virus-related cellular activities (Zhang et al., 2011; Saxena and Kumar, 2014). Isaacson and Ploegh (2009) had summarized the effect of Ub, Ubl, and deubiquitination in viral infection, and then Gu and Shi (2016) reviewed the mechanism used by viruses to bypass or employ DUBs to evade the host immune defense. As an interesting therapeutic target, the clinical development of selective DUB inhibitors has been well-reviewed (Harrigan et al., 2018). Here, we mainly summarize the recent studies on the role of DUBs in viral replication, including host-encoded- and virus-encoded DUBs, and the influence of DUBs on the innate immunity of the host. Our review aims to provide a brief insight into the above fields and highlight the potential therapeutic targets of virus infection.

\section{HOST-ENCODED DEUBIQUITINASES}

\section{Host-Encoded Deubiquitinases Regulate Viral Replication by Affecting Innate Immune Response}

The innate immune response begins with pathogen recognition. Pathogen-associated molecular patterns (PAMPs) are structural characteristics that broadly exist in various pathogens and are recognized by germline-encoded pattern-recognition receptors (PRRs). Activated PRRs initiate cellular signaling pathways which defend against the invading microbes (Akira et al., 2006). PRRs include Toll-like receptors (TLRs), RIG-I-like receptors (RLRs), NOD-like receptors (NLRs), and C-type lectin receptors (CLRs). Both TLRs and RLRs are responsible for sensing viral infection. Upon recognition, TLRs recruit adaptor proteins, including MyD88 (Myeloid differentiation primary response protein 88), TIRAP (Toll/interleukin 1 receptor domain-containing adaptor protein), TRIF (toll/interleukin 1 receptor-domain-containing adapter-inducing interferon- $\beta$ ), and TRAM (a transverse rectus abdominis), and lead to activation of the TRAF3-TBK1-IRF3 axis to induce type I IFN (IFN-I), or the TRAF6-TAK1-IKK axis to activate nuclear factor $\kappa$-light-chain-enhancer of activated $B$ cells $(\mathrm{NF}-\kappa \mathrm{B})$ and stimulate inflammatory cytokines (Kawai and Akira, 2011; Lim and Staudt, 2013; Ivashkiv and Donlin, 2014). As a typical member of the RLRs family, Retinoic acidinducible gene I (RIG-I) interacts with a mitochondrial activator of virus signaling (MAVS), the essential signaling adaptor protein of RIG-I, and causes the activation of TBK1 (TANK-binding kinase 1) and $\mathrm{IKK} \varepsilon$ (IКB kinase $\varepsilon$ ) (Kell and Gale, 2015; Chow et al., 2018). As the TLR and RIG-I signaling have crosslinks and have been well characterized, we summarize recent studies on regulating host-encoded DUBs in viral replication via TLR, RIG-I, or STING signaling (Figure 1). In most cases, host DUBs exert their deubiquitinating activity to reverse the ubiquitination and degradation of key molecular regulators of TLR or RIG-I signaling, including TRAF3 (TNF-receptor-associated factor 3), TBK1, MAVS (Mitochondria antiviral signaling protein), and other molecules, resulting in their stabilization, thereby altering the strength of the innate immune response to restrict the 


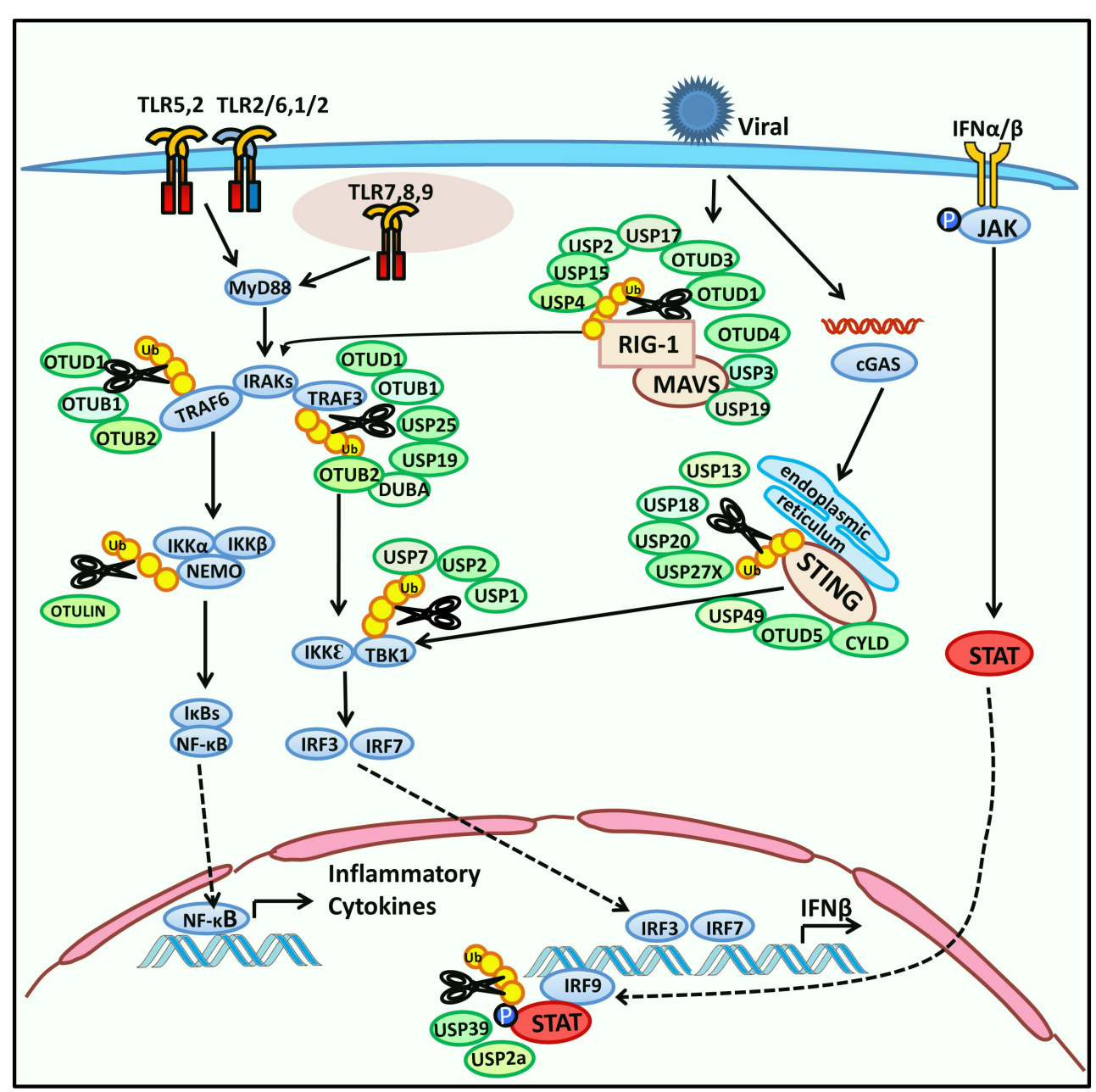

FIGURE 1 | Regulation of host-encoded DUBs in innate immune response. Toll-like receptors (TLRs) are a type of pattern-recognition receptors (PRRs) that recognize pathogen-associated molecular patterns (PAMPs) and subsequently change their conformation to initiate downstream signaling. TLRs are located on the cell membrane, phagosome membrane, endosome, and endoplasmic reticulum (TLRs on endosomes and endoplasmic reticulum are not shown). TLRs can activate the expression of NF-KB or IRF3 and subsequently induce the expression of inflammatory cytokines or IFN- $\beta$ in the nucleus. Activated TLRs recruit adaptor proteins, including TIRAP, MyD88, TRAM, and TRIF. First, the adaptors interact with IRAKs and TRAF6 and then activate NF-KB through the TAK1-IKK-IKB axis. Second, the adaptors mediate the expression of IRF3 via TRIF-TRAF3-TBK1 signaling. In addition, another PRR, RIG-I, which belongs to the RIG-I-like receptors (RLRs) family, is responsible for sensing RNA of pathogens. It interacts with MAVS, which further induces both NF-KB and IRF3. Stimulator of interferon genes (STING), located on the endoplasmic reticulum senses cytoplasmic DNA and regulates IFN signaling by activating TBK1 and IRF3. IFN- $\beta$ induces the phosphorylation of JAK and expression of interferon-stimulated genes (ISGs) by activating the downstream JAK-STAT pathway. Host-encoded DUBs interact with the above signaling molecules to modulate the innate immune response. Their deubiquitinating function and substrates are shown in the schematic.

proliferation of the virus. Located on the endoplasmic reticulum, STING (the stimulator of IFN genes) is responsible for sensing cytoplasmic DNA and exerts its function by activating TBK1 and IRF3 (IFN regulatory factor 3) thus stimulating IFN-I production (Tanaka and Chen, 2012).

Studies on host DUBs' function in innate immune response could be dated to the beginning of the 21st century. The tumor suppressor CYLD was originally reported to be a deubiquitinase that negatively regulates $\mathrm{NF}-\kappa \mathrm{B}$ via its deubiquitinase activity in 2003 (Kovalenko et al., 2003; Trompouki et al., 2003). The subsequent studies showed that CYLD is a negative regulator targeting RIG-I by the removal of K63-linked RIG-I polyubiquitin chains, resulting in the inactivation of IKK $\varepsilon / \mathrm{TBK} 1$, and eventually inhibiting IFN promoter (Friedman et al., 2008; Zhang et al., 2008). In 2018, CYLD was reported to positively regulate STING-mediated antiviral signaling by the cleavage of K48-linked ubiquitination of STING and the blockage of its degradation, thus sustaining the level of STING and triggering the antiviral response (Zhang et al., 2018b). Zinc finger protein A20 (A20) is an OTU domain DUB and also has E3 ubiquitin ligase activity. It has been reported that $\mathrm{A} 20$ functions as a potent inhibitor of NF- $\kappa$ B signaling through the cooperative activity of its two ubiquitin-editing domains or antagonizing the interactions between TRAF6, TRAF2, and cIAP1 with the E2 ligases $\mathrm{Ubc13}$ and $\mathrm{UbcH} 5 \mathrm{c}$, which are required for TRAF6 ubiquitination and NF- $\kappa$ B activation (Wertz et al., 2004; 
Shembade et al., 2010). A20 has been reported to be a negative regulator of antiviral signaling by binding to TRIF and inhibition of TRIF-mediated activation of ISRE and IFN- $\beta$ as well as Sendai virus $(\mathrm{SeV})$ triggered NF- $\mathrm{KB}$ promoter, and blocks RIG-I-induced activation of NF- $\kappa$ B-, IRF3- and IRF7-dependent promoters (Wang et al., 2004; Lin et al., 2006). So far, there are few studies of host-encoded DUBs other than USP and OTU family which regulate innate immune responses, so here we are focusing on these two DUB family members.

\section{Ubiquitin-Specific Proteases}

Among the seven families of DUB families, the USP family is the largest DUB family, with more than 60 USPs identified (Yuan T. et al., 2018). Many USPs participate in the regulation of viral replication and are widely involved in RIG-I-induced antiviral immunity, such as USP17, USP3, USP4. In 2010, USP17 was identified in virus-induced IFN signaling, whose role in viral immunology is explored much earlier. Knockdown of USP17 increases the ubiquitination level of RIG-I and another RLR, MDA5, and reduces the production of SeV-induced IRF3 and IFN- $\beta$ (Chen et al., 2010). It has been demonstrated that RIG-I K63-linked ubiquitination mediated by the E3 ubiquitin ligase tripartite motif protein 25 (TRIM25) is required for its activation and the stimulation of IFN signaling (Gack et al., 2007). In 2013, USP3 was reported to inhibit the type-I IFN pathway by binding to the K63-linked polyubiquitin chains of RIG-I and cleaving them, resulting in the negative regulation of RIG-I ubiquitination. Knockdown of USP3 promotes the phosphorylation of IRF3 and enhances the resistance of cells to viral infection (Cui et al., 2014). As a positive regulator of RIG-I-induced IFN signaling, USP4 interacts and removes K48-linked polyubiquitin chains of RIG-I and prevents RIGI from degradation. Overexpression of USP4 suppresses VSV replication, while the knockdown of USP4 has the opposite effect (Wang L. et al., 2013). There are two contradictory reports about the regulation mechanism of USP15 on antiviral signaling (Pauli et al., 2014; Zhang et al., 2015). The first research reveals that USP15 deubiquitinates K48-linked ubiquitination of TRIM25 and prevents the degradation of TRIM25, which indicates that USP15 indirectly enhances TRIM25- and RIG-Idependent production of IFN-I and the antiviral activity (Pauli et al., 2014). However, the other research claims that USP15 serves as a negative regulator of RIG-I signaling by deconjugating K63-linked polyubiquitin chains from RIG-I, resulting in the suppression of RIG-I-mediated antiviral responses. Interestingly, this research also points out that a part of this inhibition effect is independent of the DUB activity of USP15 (Zhang et al., 2015). Enterovirus 71 (EV71) infection induces the expression of host DUB USP19, and USP19 removes K63linked ubiquitination of TRAF3, thereby inhibiting the antiviral IFN signaling. Knockdown of USP19 promotes cellular antiviral immunity and represses the replication of EV-71 (Gu et al., 2017). USP21 is the same negative regulator of the IFN signaling as USP19 by targeting and deubiquitinating K63linked ubiquitination of RIG-I, though the specific site of deubiquitination has not been clarified (Fan et al., 2014). USP25 has been identified as a regulator of TLR signaling by removing the cIAP2 (cellular inhibitor of apoptosis 2)-mediated K48-linked ubiquitination of TRAF3, resulting in the blockage of TRAF3 degradation. The deficiency of USP25 enhances the extent of ubiquitination of TRAF3 and accelerates its degradation after TLR4 activation, which potentiates TLR4-induced activation of MAPK and NF- $\mathrm{BB}$ signaling, but suppresses the activation of IRF3 (IFN regulatory factor 3). Therefore, USP25 enables a balance between proinflammatory cytokines and type I IFNs by maintaining cellular TRAF3 level (Zhong et al., 2013).

USP1 forms a complex with USP1-associated factor 1 (UAF1), which reduces K48-linked ubiquitination of TBK1 and stabilizes it, resulting in the downstream activation of IRF3 and promotion of IFN- $\beta$ secretion. The USP1-UAF1 inhibitor ML323 suppresses the expression of IFN- $\beta$ and enhances virus replication in vitro and in vivo. This finding indicates a positive-regulatory effect of USP1 on IFN signaling (Yu et al., 2017). Another study reported that in contrast to USP1 and USP39, USP7 acts as a negative regulator of IFN signaling. Overexpression of USP7 enhances the stabilization of the E3 ligase TRIM27, thus promoting the ubiquitination and degradation of TBK1 and vesicular stomatitis virus (VSV) replication, whereas knockdown and knockout of endogenous USP7 inhibit TBK1 ubiquitination and degradation and increase IFN- $\beta$ expression (Cai et al., 2018). Like USP7, USP5 is a restrictive factor for red-spotted grouper nervous necrosis virus (RGNNV)-induced IFN response in sea perch. Overexpression of USP5 leads to inhibition of other RLR signaling pathway-related genes, including MAVS, TRAF3, and TBK1, and strongly represses the IFN-I promoter's activation in zebra fish increases RGNNV replication in vitro. However, the mechanism by which USP5 influences RLR signaling genes needs to be elucidated further (Jia et al., 2020). Knockdown of USP39, another positive regulator of the IFN pathway, notably promotes viral replication. Interestingly, USP39 does not influence IFN-I production but affects IFN downstream JAK/STAT signaling. USP39 downregulates STAT K6-linked ubiquitination, thus stabilizing STAT (Peng et al., 2020). USP2a also targets STAT and functions as a regulator of antiviral signaling. STAT is mainly located in the nucleus, and USP2a could translocate into the nucleus and reduce the K48-linked ubiquitination and degradation of pY701-STAT1 (STAT activation depends on phosphorylation at tyrosine 701). Therefore, USP2a maintains the level of pY701-STAT induced by IFN and promotes antiviral immunity (Ren et al., 2016). USP $2 b$ targets TBK 1 and negatively regulates IFN- $\beta$ signaling by the cleavage of K63-linked polyubiquitin chains of TBK1, thus inhibiting the kinase activity of TBK1. Overexpression of USP2b promotes the replication of vesicular stomatitis virus (VSV), whereas the knockdown of USP2b represses VSV replication (Zhang et al., 2014).

As a negative regulator of cellular antiviral responses that targets STING, USP13 deconjugates K27- and K63-linked polyubiquitin chains of STING and then prevents the recruitment of TBK1 to STING. The knockdown of USP13 activates IRF3 and NF- $\mathrm{KB}$ and enhances antiviral immunity. Consistently, the deficiency of USP13 inhibits Herpes simplex virus (HSV-1) infection (Sun et al., 2017). USP49 has a similar function as USP13 (Ye et al., 2019). USP18 recruits USP20 and deconjugates 
K48-linked ubiquitination of STING, thereby protecting STING from proteasomal degradation and promoting the production of type-I IFN. The knockdown of USP20 or USP18 promotes STING ubiquitination and degradation and impairs IRF3 and $\mathrm{NF}-\kappa \mathrm{B}$ pathways, thereby reducing the resistance of mice to HSV-1 infection (Zhang et al., 2016). USP27X also targets, and the mechanism involves cyclic GMP-AMP synthase (cGAS), a cytosolic DNA sensor catalyzing the formation of a second messenger cGAMP. cGAMP binds to STING and promotes the IFN-I signaling. USP27X interacts with cGAS and removes its K48-linked ubiquitination, thereby leading to the stabilization of cGAS and the enhancement of IFN production (Guo et al., 2019).

\section{Ovarian Tumor Proteases}

Deubiquitinases in the OTU superfamily were originally identified from different organisms and affect antiviral immunity as well as virus proliferation (Kayagaki et al., 2007; Li et al., 2010). Deubiquitinating enzyme A (DUBA) was identified in 2007 to act as a negative regulator of IFN signaling, which removes K63-linked ubiquitination of TRAF3, resulting in the dissociation of TRAF3 from TBK1 (Kayagaki et al., 2007). OTUB1 and OTUB2 negatively regulate type-I IFN signaling by deubiquitinating TRAF3 and TRAF6 after viral infection (Li et al., 2010). OTUD1 could also inhibit IFN response. OTUD1 could be induced by an RNA virus and could upregulate the level of protein Smurf1. Smurf1 could ubiquitinate and degrade each component of the MAVS/TRAF3/TRAF6 signalosome (Zhang et al., 2018a). OTUD3 is an acetylation-dependent DUB. Its DUB activity relies on K129 acetylation, and it could remove the K63-linked ubiquitination of MAVS, hence repressing antiviral response. OTUD3 acetylation would be removed upon virus infection, and the DUB activity would be blocked. Therefore, OTUD3 is controlled to timely response to virus infection (Zhang et al., 2020). OTUD5 exerts DUB activity by cleaving STING K48, enhancing STING stability, and thus promoting type-I IFN signaling (Guo et al., 2020). Similarly, OTUD4 deubiquitinates and stabilizes MAVS and promotes antiviral signaling. Knockdown of OTUD4 inhibits the activation of NF$\kappa \mathrm{B}$ and IRF3, resulting in the suppression of their downstream genes, thus enabling the VSV replication (Liuyu et al., 2019). OTULIN is an ovarian tumor domain deubiquitinase that possesses linear linkage specificity. PRRSV infection enhances the expression of OTULIN, and overexpression of OTULIN increases PRRSV propagation. OTULIN is recruited by PRRSV Nsp11 and removes linear ubiquitination targeting NEMO, a subunit of the IKK complex, resulting in the reduction of IFN-I production (Su et al., 2018).

\section{Host-Encoded Deubiquitinases Modulate Virus Replication via Viral Proteins}

In addition to modulating innate immune signaling pathways, host DUBs also regulate viral replication via the interaction with virus-encoded proteins. Due to the selective pressure of evolution, viruses have evolved to recruit host proteins to assist their propagation, and host deubiquitinases are widely involved (Table 1). USP7 is the first identified DUB that interacts with
ICP0 of HSV-1, mediating the stability of ICP0 or modulating TLR-mediated innate response (Everett et al., 1997; Boutell et al., 2005; Daubeuf et al., 2009). USP7 has been demonstrated to participate in the replication of multiple viruses, including Epstein-Barr virus (EBV), Merkel cell polyomavirus (MCPyV), and Human immunodeficiency virus type 1 (HIV-1) (Holowaty and Frappier, 2004). USP7 directly binds to the large T (LT)antigen of $\mathrm{MCPyV}$, an early viral gene product that plays a significant role in viral replication, which promotes the binding affinity of LT to the viral origin of replication and decreases viral DNA replication. This process is not related to the deubiquitinase activity of USP7 (Czech-Sioli et al., 2020). USP7 also serves as an enhancer of viral replication. Inhibition of USP7 decreases the replication of human adenoviral species $\mathrm{C}$ (HAdV-C5), most adenoviral species $\mathrm{A}$ as well as clinical isolates, and HIV (Ali et al., 2017; Kosulin et al., 2018). HIV Tat is produced in the early phase of HIV infection and is mainly responsible for transacting transcription and promoting viral production. USP7 stabilizes Tat by deubiquitylating and blocking it from proteasomal degradation, resulting in the promotion of virus propagation (Ali et al., 2017). In EBV infected cells, the EBNA1 protein binds to specific recognition sites oriP in the latent origin of replication required for the viral genome's replication and maintenance. USP7 greatly stimulates EBNA1-DNA interactions and enhances the ability of EBNA1 to activate transcription by modifying histone in a deubiquitinase-dependent manner (Sarkari et al., 2009). Similarly, in Kaposi's sarcoma herpesvirus (KSHV), USP7 interacts with the viral latency-associated nuclear antigen 1 (LANA), which is involved in latent viral replication and maintenance of the viral genome, thus enhancing the latent viral DNA replication of KSHV (Holowaty et al., 2003; Jager et al., 2012). vIRF1 of KSHV was identified as a novel interaction partner of USP7, which deregulates USP7 to inhibit p53-mediated antiviral responses (Chavoshi et al., 2016).

In high-risk human papillomavirus (HPV)-induced cancer, USP46 recruited by oncoprotein E6 leads to deubiquitination and stabilization of Cdt2/DTL, a component of the E3 ligase CRL4 ${ }^{\mathrm{Cdt} 2}$, and represses the level of epigenetic regulator Set8, which promotes cell proliferation. Thus, depletion of USP46 inhibits HPV-transformation-induced tumor growth through the E6-USP46-Cdt2-Set8 pathway (Kiran et al., 2018). HPV E1 helicase, which possesses DNA unwinding activity and enhances viral DNA replication, could form a complex with UAF1 and any one of USP1, USP12 and USP46. Besides USP1, the catalytic activity-negative USP12 and USP46 also decrease viral replication, and E1-UAF1 binding is essential for the effect (Lehoux et al., 2014). Therefore, USP1, USP12, and USP46 promote viral replication via interacting with the E1UAF1 complex.

Similarly, inhibition of USP14 causes the repression of replication of several flaviviruses, indicating the crucial role of USP14 in viral propagation (Nag and Finley, 2012; Perry et al., 2012). WP1130, a small molecule inhibitor, can inhibit Murine norovirus 1 (MNV-1) replication, and chemical proteomics showed that USP14 is the target of WP1130. The downregulation of USP14 by pharmacologic inhibition or siRNA-mediated knockdown reduces the expression of the MNV-1 non-structural 
TABLE 1 | Host-encoded DUBs and the targeted viruses, proteins, or genes.

\begin{tabular}{|c|c|c|c|}
\hline Host-encoded DUBs & $\begin{array}{l}\text { Targeted viruses or genes, } \\
\text { proteins }\end{array}$ & The mechanism & References \\
\hline USP1/USP12/USP46 & $\begin{array}{l}\text { Human papillomavirus (HPV) E1 } \\
\text { helicase }\end{array}$ & Unwinding DNA and enhancing viral DNA replication & Lehoux et al., 2014 \\
\hline USP14 & $\begin{array}{l}\text { Murine norovirus } 1 \text { (MNV-1) VPg } \\
\text { gene }\end{array}$ & Non-structural gene & Perry et al., 2012 \\
\hline \multirow[t]{7}{*}{ USP 7} & HIV-1 Tat & Promoting viral production & Ali et al., 2017 \\
\hline & $\begin{array}{l}\text { Herpes simplex virus type } 1 \\
(\mathrm{HSV}-1) \text { ICPO (Vmw110) }\end{array}$ & Non-specific activator of gene expression & Everett et al., 1997 \\
\hline & Epstein-Barr virus (EBV) EBNA1 & Initiating EBV latent genome replication & Sarkari et al., 2009 \\
\hline & $\begin{array}{l}\text { Kaposi's sarcoma herpesvirus } \\
\text { (KSHV) LANA } \\
\text { vIRF1 }\end{array}$ & $\begin{array}{l}\text { Working in latent viral replication } \\
\text { Inhibit p53-mediated antiviral responses }\end{array}$ & Chavoshi et al., 2016 \\
\hline & Merkel cell polyomavirus (MCPyV) & Working in viral replication & Czech-Sioli et al., 2020 \\
\hline & $\begin{array}{l}\text { red-spotted grouper nervous } \\
\text { necrosis virus (RGNNV) }\end{array}$ & Strongly represses the activation of the IFN-I promoter & Jia et al., 2020 \\
\hline & TRIM27 & Enhances the stabilization of the E3 ligase TRIM27 & Cai et al., 2018 \\
\hline \multirow[t]{2}{*}{ USP15 } & HIV Nef & Necessary for AIDS pathogenicity & Pyeon et al., 2016 \\
\hline & HIV Gag & HIV structural protein & \\
\hline USP11 & Influenza A virus RNA & A component of viral RNA replication complex & Liao et al., 2010 \\
\hline OTULIN & PRRSV Nsp11 & $\begin{array}{l}\text { OTULIN is recruited by PRRSV Nsp11 and removes linear } \\
\text { ubiquitination targeting NEMO }\end{array}$ & Su et al., 2018 \\
\hline USP19, DUBA & TRAF3 & Removes K63-linked ubiquitination of TRAF3 & $\begin{array}{l}\text { Kayagaki et al., 2007; Gu } \\
\text { et al., } 2017\end{array}$ \\
\hline USP25 & TRAF3 & The enhancement of TRAF3 degradation & Zhong et al., 2013 \\
\hline CYLD; USP18 and USP20 & STING & The cleavage of K48-linked ubiquitination of STING & $\begin{array}{l}\text { Zhang et al., 2016; Zhang } \\
\text { et al., 2018b }\end{array}$ \\
\hline USP13/49 & STING & $\begin{array}{l}\text { Deconjugates K27- and K63-linked polyubiquitin chains of } \\
\text { STING }\end{array}$ & $\begin{array}{l}\text { Sun et al., 2017; Ye et al., } \\
2019\end{array}$ \\
\hline USP17 & $R|G-|$ & Increases the ubiquitination level of RIG-I & Chen et al., 2010 \\
\hline USP3/21/19 & RIG-I & Removes K63-linked polyubiquitin chains of RIG-I & $\begin{array}{l}\text { Cui et al., 2014; Fan et al., } \\
\qquad 2014\end{array}$ \\
\hline USP4 & $R|G-|$ & $\begin{array}{l}\text { Interacts and removes K48-linked polyubiquitin chains of } \\
\text { RIG-I }\end{array}$ & Wang L. et al., 2013 \\
\hline USP15 & TRIM25/RIG-I & $\begin{array}{l}\text { Enhanced the TRIM25- and RIG-I-Dependent production of } \\
\text { IFN-I and suppressed RNA virus replication }\end{array}$ & $\begin{array}{l}\text { Pauli et al., 2014; Zhang } \\
\text { et al., } 2015\end{array}$ \\
\hline USP1 & TBK1 & Reduces K48-linked ubiquitination of TBK1 and stabilizes it & Yu et al., 2017 \\
\hline USP2a & STAT & $\begin{array}{l}\text { Reduce the K48-linked ubiquitination and degradation of } \\
\text { pY701-STAT1 }\end{array}$ & Ren et al., 2016 \\
\hline USP39 & STAT & $\begin{array}{l}\text { Downregulates STAT K6-linked ubiquitination, thus } \\
\text { stabilizing STAT }\end{array}$ & Peng et al., 2020 \\
\hline USP2b & TBK1 & Inhibits the kinase activity of TBK1 & Zhang et al., 2014 \\
\hline USP27X & cGAS-STING & Removes cGAS K48-linked ubiquitination & Guo et al., 2019 \\
\hline DUBA & TRAF3 & Removes K63-linked ubiquitination of TRAF3 & Kayagaki et al., 2007 \\
\hline OTUB1, OTUB2 & TRAF3 and TRAF6 & Deubiquitinating TRAF3 and TRAF6 & Li et al., 2010 \\
\hline OTUD1 & Smurf1 & Upregulate the level of protein Smurf1 & Zhang et al., 2018a \\
\hline OTUD3, OTUD4 & MAVS & Deubiquitinates and stabilizes MAVS & $\begin{array}{l}\text { Liuyu et al., 2019; Zhang } \\
\text { et al., } 2020\end{array}$ \\
\hline OTUD5 & STING & Cleaving STING K48, enhancing STING stability & Guo et al., 2020 \\
\hline
\end{tabular}

gene VPg, suggesting the essential role of USP14 in effective MNV-1 inhibition (Perry et al., 2012).

Host DUBs also block the activity of crucial proteins during viral replication, thus exhibiting a negative regulatory function. Liao et al. reported that downregulation of USP11 results in higher level of influenza A virus (IAV) RNA, indicating that USP11 inhibits IAV replication. Moreover, the inhibitory effect of USP11 on viral genome replication requires its deubiquitinase activity. USP11 interacts with and deubiquitinates the nucleoprotein (NP) protein, a component of the viral RNA replication complex (Liao et al., 2010). In contrast to the positive role of USP7 in HIV-1 replication, USP15 represses the replication of HIV-1 by inducing the degradation of HIV-1 Nef and Gag proteins (Pyeon et al., 2016). 


\section{VIRUS-ENCODED DEUBIQUITINASES}

Deubiquitinases are widely presented in various viruses and significantly influence viral activity. During viral infection, a set of DUBs encoded by viruses mainly target various signaling molecules of innate immune pathways to suppress antiviral immunity, thus ensuring viral replication (Kumari and Kumar, 2018). In addition, some virus-encoded DUBs regulate viral replication through other mechanisms or mechanisms remaining unknown. Most viral DUB activity is mediated by papain-like proteases (PLPs) (Zheng et al., 2008; Frieman et al., 2009; Wang G. et al., 2011; Sun et al., 2012; van Kasteren et al., 2013; Xing et al., 2013; Chen et al., 2014; Yang et al., 2014; Yuan et al., 2015; Li et al., 2016). The adenovirus protease adenain was initially demonstrated to possess a deubiquitinating function in in vitro experiments (Balakirev et al., 2002). Then viral PLPs encoded by coronavirus family member such as SARS-CoV was reported to remove ubiquitin from substrate proteins (Barretto et al., 2005; Lindner et al., 2005; Bekes et al., 2016; Shin et al., 2020). UL36 encoded by HSV-1 and Marek's disease virus (MDV), UL48 of HCMV are ubiquitin-specific cysteine proteases and have deubiquitinating activity (Kattenhorn et al., 2005; Wang et al., 2006; Jarosinski et al., 2007). DUB activity is strictly conserved in several other herpesviruses such as EBV, which encodes BPLF1 exhibiting deubiquitinating activity (Whitehurst et al., 2009). DUBs encoded by other viral genes are relatively few. For example, the DUB of nairoviruses resides in the polymerase protein but is not essential for RNA replication (van Kasteren et al., 2012). Previous studies have systematically summarized the role of viral DUBs in innate immunity (Gu and Shi, 2016;

TABLE 2 | Virus-encoded DUBs and the targeted proteins or genes.

\begin{tabular}{|c|c|c|c|}
\hline Virus-encoded DUBs & Targeted protein(s) or gene(s) & Mechanism & References \\
\hline $\begin{array}{l}\text { Adenovirus protease } \\
\text { Adenain }\end{array}$ & $\mathrm{N} / \mathrm{A}$ & Deubiquitinates a number of cellular proteins & Balakirev et al., 2002 \\
\hline \multirow[t]{2}{*}{ SARS PLP } & ISG15 & $\begin{array}{l}\text { Cleave replicase substrates; cleave K48-linked polyUb } \\
\text { chains of ISG15 }\end{array}$ & $\begin{array}{l}\text { Barretto et al., 2005; Lindner } \\
\text { et al., 2005; Bekes et al., 2016; } \\
\text { Shin et al., } 2020\end{array}$ \\
\hline & TRAF3, TRAF6 & $\begin{array}{l}\text { Inhibits the production of IFNs and pro-inflammatory } \\
\text { cytokines }\end{array}$ & Li et al., 2016 \\
\hline HcoV-NL63 PLP2 & $\mathrm{N} / \mathrm{A}$ & $\begin{array}{l}\text { Antagonizes the induction of IFN-I independent of protease } \\
\text { and DUB activity }\end{array}$ & $\begin{array}{l}\text { Clementz et al., 2010; Yuan } \\
\text { et al., } 2015\end{array}$ \\
\hline \multirow[t]{3}{*}{ HSV-1 UL36 } & $\begin{array}{l}\text { Proliferating cell nuclear antigen } \\
\text { (PCNA) }\end{array}$ & $\begin{array}{l}\text { Blocks the polymerase- } \eta \text {-mediated DNA damage-response } \\
\text { translation synthesis (TLS) pathway }\end{array}$ & Kattenhorn et al., 2005 \\
\hline & $\begin{array}{l}\text { TRAF3, } \\
\text { ISRE promoter }\end{array}$ & $\begin{array}{l}\text { Inhibits IFN-I production or counteracts the IFN-I-mediated } \\
\text { signaling pathway }\end{array}$ & $\begin{array}{l}\text { Wang S. et al., 2013; Yuan H. } \\
\text { et al., } 2018\end{array}$ \\
\hline & $1 \kappa \mathrm{B} \alpha$ & $\begin{array}{l}\text { The inactivation of the NF- } \mathrm{kB} \text { pathway and the inhibition of } \\
\text { IFN- } \beta \text { production }\end{array}$ & Ye et al., 2017 \\
\hline MDV UL36 & $\mathrm{N} / \mathrm{A}$ & Contributes to malignant outgrowths & Jarosinski et al., 2007 \\
\hline \multirow[t]{3}{*}{ HCMV UL48 } & $\mathrm{N} / \mathrm{A}$ & Facilitates production of infectious virus & $\begin{array}{l}\text { Wang et al., 2006; Kim et al., } \\
\qquad 2009\end{array}$ \\
\hline & $\begin{array}{l}\text { TRAF6, TRAF3, IRAK1, IRF7, } \\
\text { STING }\end{array}$ & $\begin{array}{l}\text { Promotes oncogenesis by inhibiting innate immunity of the } \\
\text { host }\end{array}$ & Kumari et al., 2017 \\
\hline & RIP1 & Inhibits TNF $\alpha$-induced NF-кB activation & Kwon et al., 2017 \\
\hline \multirow[t]{3}{*}{ EBV BPLF1 } & EBV ribonucleotide reductase (RR) & $\begin{array}{l}\text { Interacts with, deubiquitinates, and influences the activity of } \\
\text { the EBV RR }\end{array}$ & Whitehurst et al., 2009 \\
\hline & ІкB $\alpha$, TRAF6, NEMO & Suppresses TLR-mediated activation of NF-кB & $\begin{array}{l}\text { Saito et al., 2013; van Gent } \\
\text { et al., } 2014\end{array}$ \\
\hline & PCNA & Attenuates polymerase $\eta$ recruitment to DNA damage sites & Whitehurst et al., 2012 \\
\hline CCHFV OTU & NP & $\begin{array}{l}\text { Associating with viral genomic RNA to form RNP } \\
\text { complexes, initiate replication or transcription }\end{array}$ & Scholte et al., 2019 \\
\hline KSHV ORF64 & $R \mid G-1$ & Inhibition of RIG-I-mediated signaling & Inn et al., 2011 \\
\hline Arteri- and nairovirus DUBs & $R \mid G-1$ & Control innate immune signaling & van Kasteren et al., 2012 \\
\hline TYMV PRO domain & 66K RdRp & Ensures the replication of viral RNA & Fieulaine et al., 2020 \\
\hline HEV PCP & RIG-I, TBK1 & Reduces IFN production & Nan et al., 2014 \\
\hline FMDV Ppro & RIG-1, TBK1, TRAF3, TRAF6 & Blocks the IFN- $\beta$ promoter & Wang D. et al., 2011 \\
\hline PEDV PLP2 & IRF3 & Negatively regulates type I interferon pathway & Xing et al., 2013 \\
\hline TGEV PL1 & RIG-I, STING & Antagonizes production of IFN- $\beta$ & Hu et al., 2017 \\
\hline PRRSV nsp2 & $\mid \kappa B \alpha$ & $\begin{array}{l}\text { Antagonizes the type I interferon induction by interfering } \\
\text { with the NF-kappaB signaling pathway }\end{array}$ & Sun et al., 2010 \\
\hline MHV-A59 PLP2 & $\begin{array}{l}\text { IRF3 } \\
\text { TBK1 }\end{array}$ & $\begin{array}{l}\text { Blocks IRF3-, TBK1- and CARDIF-mediated IFN- } \beta \text { reporter } \\
\text { activity }\end{array}$ & $\begin{array}{l}\text { Zheng et al., 2008; Wang G. } \\
\text { et al., } 2011\end{array}$ \\
\hline
\end{tabular}

N/A represents not applicable. 
Zheng and Gao, 2020), here, we focus on the recent studies on how viral DUBs modulate the innate immune response and detail the signaling pathways that involve viral DUBs (Table 2).

\section{Effect of Virus-Encoded Deubiquitinases on Retinoic Acid-Inducible Gene-I and Toll-Like Receptor Signaling}

Viral DUB could influence the TLR pathway to antagonize innate immunity, and PLP2 encoded by Human coronavirus NL63 (HCoV-NL63) is a typical DUB targeting TLR signaling. HCoV-NL63 PLP2 was identified to possess DUB activity, and it could cleave both K48- and K63-linked polyubiquitin chains, thereby antagonizing IFN, although the inhibition effect is independent of its DUB activity (Clementz et al., 2010). In 2015, another study suggested one potential mechanism of HCoV-NL63 PLP2 antagonism to IFN signaling, but it is associated with PLP2 DUB activity. PLP2 is claimed to induce p53 degradation via deubiquitination and stabilization of the oncoprotein MDM2, an E3 ligase degrading p53. p53 could activate the transcription of IRF7. Hence, PLP2 blocks IFN- $\beta$ signaling through the MDM2-p53-IRF7 pathway and facilitates viral replication (Yuan et al., 2015).

Multiple viral DUBs mainly target RIG-I signaling to regulate IFN response. The DUB activity of Crimean-Congo Hemorrhagic Fever virus (CCHFV) OTU is essential for inhibiting RIG-Imediated IFN- $\beta$ response and inactivated OTU DUB suppresses viral replication. OTU represses the RIG-I-mediated IFN- $\beta$ response by removing ubiquitin (Ub) from RIG-I CARDs. Moreover, OTU DUB also inhibits the IFN- $\beta$ response by blocking the activation of both IRF3 and NF- $\kappa \mathrm{B}$, indicating that CCHFV OTU DUB ensures the sufficient replication of the virus via multiple cellular signaling pathways (Scholte et al., 2017). KSHV ORF64 DUB, both arteri- and nairovirus DUBs decrease the ubiquitination of RIG-I, thus inactivating RIG-I-mediated IFN signaling (Inn et al., 2011; van Kasteren et al., 2012). DUBs can also repress MAVS-mediated IFN- $\beta$ induction (van Kasteren et al., 2012). The interaction between herpesvirus BPLF1 and the 14-3-3-TRIM25 complex is essential for the induction of TRIM25 aggregates. TRIM25 ubiquitinates RIG-I, thus promoting RIG-Itriggered IFN signaling (Gupta et al., 2019).

Some viral DUBs can act on various RIG-I and TLR pathways adaptors. SARS-CoV infection inhibits IFN production as well as the upregulation of IFN-stimulated genes. SARSCoV PLP interacts with IRF3 to block its phosphorylation and translocation into the nucleus and interrupts IRF3-mediated IFN signaling of either RIG-I or TLR pathway (Devaraj et al., 2007). However, a later study reported that SARS-CoV PLP does not directly interact with IRF3 and inhibit IRF3 phosphorylation in vitro but suppresses IRF3 signaling. PLP blocks both IRF3 and NF- $\mathrm{B}$ signaling by deubiquitinating $\mathrm{IKB} \alpha$, while DUB activity of PLP is necessary for pathway antagonism but not sufficient by itself (Frieman et al., 2009). In addition, SARS coronavirus PLP also suppresses the TLR7 signaling pathway by removing K63-linked polyubiquitin of TRAF3 and TRAF6, thereby inhibiting the production of IFNs and pro-inflammatory cytokines (Li et al., 2016). Seneca Valley Virus (SVV) 3C protease represses the ubiquitination of RIG-I, TBK1, and TRAF3, thus inhibiting the expression of IFN- $\beta$ and promoting virus replication (Xue et al., 2018). The PCP domain of hepatitis E virus (HEV) deubiquitinates RIG-I and TBK-1, thereby reducing IFN production (Nan et al., 2014). The leader proteinase (L ${ }^{\mathrm{pro}}$ ) of the foot-and-mouth disease virus (FMDV) has DUB activity and strongly reduces ubiquitination of several key molecular regulators in the IFN-I response pathway, including RIG-1, TBK1, TRAF3, and TRAF6. Loss of DUB activity abolishes the ability of $L^{\text {pro }}$ to block the IFN- $\beta$ promoter (Wang D. et al., 2011).

\section{Effect of Virus-Encoded Deubiquitinases on STING Signaling}

Some virus-encoded DUBs act on STING and influence downstream signaling. HSV-1 VP1-2 blocks IFN-I production by directly interacting with and deubiquitinating STING. In contrast, the VP1-2 mutant that lacks DUB activity enhances IFN expression due to increased STING ubiquitination as well as STING, TBK1, and IRF3 phosphorylation (Bodda et al., 2020). In addition, ORF64 DUB of MHV68 is essential for antagonizing the STING-dependent pathway which is induced by viral genomic DNA (Sun et al., 2015).

Human cytomegalovirus (HCMV) pUL48 blocks PRRmediated IFN-I signaling through deubiquitinating a variety of key molecules, including STING, TRAF3, TRAF6, IRAK1, and IRF7 (Kumari et al., 2017). Upon ectopic expression, both CoV-NL63 PLP2 and SARS-CoV membrane-anchored PLpro domain (PLpro-TM) inhibit the formation of STING dimer and block the assembly of STING-MAVS-TBK1/IKK $\varepsilon$ complexes, thus inhibiting the activation of IRF3 and disrupting the signaling of IFN induction (Sun et al., 2012). It has also been demonstrated that SARS-Cov PLpro-TM represses the ubiquitination of RIGI, STING, TRAF3, TBK1, and IRF3, thus inhibiting the assembly of the STING-TRAF3-TBK1 complex and the activation of IFN expression (Chen et al., 2014).

Some DUBs directly interact with RIG-I or STING and deubiquitinate them, resulting in suppression of STING- and RIG-I-mediated IFN- $\beta$ signaling, such as porcine epidemic diarrhea virus (PEDV) PLP2 and transmissible gastroenteritis virus (TGEV) PL1 (Xing et al., 2013; Hu et al., 2017).

\section{Effect of Virus-Encoded Deubiquitinases on NF- $\kappa$ B Signaling}

Some viral DUBs target NF-кB signaling to manipulate immune responses (Sun et al., 2010; Kwon et al., 2017; Ye et al., 2017). HSV-1 UL36 and porcine reproductive and respiratory syndrome virus (PRRSV) nsp2 both deubiquitinate K48-linked I $\mathrm{B} \alpha$ and prevent its degradation, resulting in the inactivation of the NF- $\kappa \mathrm{B}$ pathway and the inhibition of IFN- $\beta$ production (Sun et al., 2010; Ye et al., 2017). UL48 and UL45 encoded by HCMV that contain DUB activity, target receptor-interacting protein kinase 1 to inhibit NF-кB signaling (Kwon et al., 2017). EBV BPLF1 deubiquitinates I $\mathrm{B} \alpha$, TRAF6 and NEMO, thus suppressing the activation of the NF- $\kappa \mathrm{B}$ pathway at multiple steps. BPLF1 also inhibits NF- $\kappa$ B upstream TLR signaling, and reduces the production of IL-8 (van Gent et al., 2014). 
EBV BPLF1 deubiquitinates TRAF6, which is further associated with latent membrane protein 1 (LMP1) and inhibits NF- $\kappa$ B signaling, thereby increasing EBV DNA replication (Saito et al., 2013). SARS-CoV PLP antagonizes IFN and NF- $\kappa B$ signaling pathway by interfering with the activation of the important signaling proteins, IRF3 and $\mathrm{I} \kappa \mathrm{B} \alpha$ in the respective pathways (Frieman et al., 2009).

\section{Effect of Virus-Encoded Deubiquitinases on Crosslinking Signaling Molecules}

Besides the DUBs listed above, some viral DUBs act on the common downstream molecules of the TLR/RIG-I/STING signaling pathways. MHV-A59 PLP2 deubiquitinases IRF3 and inhibits its nuclear translocation via its DUB activity, thereby blocking IRF3-, TBK1-, and CARDIF-mediated IFN- $\beta$ reporter activity (Zheng et al., 2008). Further studies also show that MHVA59 PLP2 deubiquitinates TBK1 and inhibits its kinase activity, thereby preventing IRF3 from phosphorylation and inactivating IFN- $\beta$ signaling (Wang G. et al., 2011). HSV-1 UL36USP deubiquitinates TRAF3 and prevents recruitment of TBK1, and inactivates the IFN- $\beta$ promoter (Wang S. et al., 2013). It also binds to the IFNAR2 subunit, thus preventing JAK1-IFNAR2 interaction. Therefore, UL36USP antagonizes IFN-mediated JAKs and STAT activation (Yuan H. et al., 2018). MERS-Cov PLpro inhibits IRF3 phosphorylation and nuclear translocation, thus antagonizing the IFN- $\beta$ pathway (Yang et al., 2014).

\section{Other Mechanisms of Virus-Encoded Deubiquitinases in the Regulation of Viral Replication}

In several RNA viruses, virus-encoded DUBs affect and mediate viral replication. CCHFV OTU is required for viral replication, and occupancy of the synthetic ubiquitin variant (UbV-CC4) on CCHFV OTU directly interrupts viral RNA synthesis, thus blocking viral replication without targeting IFN signaling. CCHFV replication requires NP protein to associate with viral genomic RNA to form ribonucleoprotein (RNP) complexes and then interact with the $\mathrm{L}$ protein to initiate replication or transcription. In the presence of UbV-CC4, fewer NPs interact with the $\mathrm{L}$ protein, which indicates that UbV-CC4 inhibits CCHFV replication by interfering with the formation of replication complexes (Scholte et al., 2019). Turnip yellow mosaic virus (TYMV) PRO/DUB enzyme mediates the RNAdependent RNA polymerase (RdRp) level, thereby regulating viral replication. The PRO domain cleaves TYMV-encoded $206 \mathrm{~K}$ polyprotein and produces $66 \mathrm{~K}$ RdRp. RdRp undergoes ubiquitination and degradation, whereas the DUB activity inhibits the degradation of the $66 \mathrm{~K} \mathrm{RdRp}$ and ensures the replication of viral RNA (Fieulaine et al., 2020). Among DNA viruses, HSV UL36USP and EBV BPLF1 enhance the sensitivity of cells to DNA-damaging agents to facilitate virus proliferation through its DUB activity (Whitehurst et al., 2012; Dong et al., 2017). In brief, UL36USP or BPLF1 deubiquitinates proliferating cell nuclear antigen (PCNA) and inhibits the subsequent formation of polymerase- $\eta$ (pol- $\eta$ ) foci, thereby blocking the pol$\eta$-mediated DNA damage-response translation synthesis (TLS) pathway (Dong et al., 2017).

Some DUB-mediated mechanisms have not yet been elucidated. PRRSV PLP2 possesses DUB activity and is essential for viral replication. However, the DUB activity is independent of the TNF- $\alpha$ pathway (Zhou et al., 2019). CCHFV L protein exhibits DUB activity but does not affect virus proliferation and innate immune responses (Tchesnokov et al., 2020). The reduction of FMDV DUB activity results in virus attenuation, but it is independent of interference with the expression of IFN (Medina et al., 2020). Murine cytomegalovirus (MCMV) encodes M48 DUB and MCK2 (MCMV-encoded chemokine 2), a viral $\mathrm{C}-\mathrm{C}$ chemokine that enhances the host immune response. Blocking M48 DUB activity reduces MCMV replication, at least in the natural host, and promotes MCK2-induced immune response (Hilterbrand et al., 2017).

\section{DEUBIQUITINASES SERVE AS TARGETS FOR THERAPY}

Being intrinsically attractive targets for drug development, the progress in the development of DUBs inhibitors or pharmacological modulation of DUB activities, in particular, the disease ranging from oncology to neurodegeneration, have been well-reviewed (Harrigan et al., 2018). As DUBs are crucial for virus replication, and participate in multiple signaling pathways during immune response, they present ideal targets for diagnosing and treating viral infections.

Perry et al. (2012) demonstrated that WP1130, a small molecule inhibitor of a subset of cellular DUBs, displays antiviral activity against murine and human norovirus, suggesting the importance of DUBs in modulating virus replication. Compound 9, a novel small molecule inhibitor derived from WP1130, markedly reduces the replication of murine norovirus, and amplifies the Norwalk virus genome (Charbonneau et al., 2014). A set of WP1130 derivatives retain the broad-spectrum antiviral function, acting on a variety of RNA viruses, including Sindbis virus and LaCrosse virus (Gonzalez-Hernandez et al., 2014). In addition, the 2-cyano-3-acrylamide compound C6 also facilitates the suppression of intracellular replication of murine norovirus by repressing DUB activity (Passalacqua et al., 2016). Overexpression of gga-miR-30d reduces the proliferation of infectious bronchitis virus (IBV), and USP47 is a target of ggamiR-30d in cells (Li et al., 2020). The DUBs inhibitors P22077 and PR-619 targeting USP7 and USP47 impair Gag processing, thereby blocking HIV-1 replication (Setz et al., 2017).

Efforts have also been focused on developing inhibitors against virus DUBs, and some have shown promise to be efficient antiviral drugs. The inhibitors targeting EBV DUB BPLF1, or thiopurine analog 6-mercaptopurine (6MP) and 6-thioguanine (6TG) targeting SARS-CoV PLpro all have been proved to be effective and promising new therapeutic strategies (Chen et al., 2009; Atkins et al., 2020). Thiopurine analog 6MP and 6TG that have long been used in cancer chemotherapy were found not only to be specific inhibitors for the SARS-CoV PLpro but also 
to be potential inhibitors of USP14 by computer docking analysis (Chen et al., 2009). GRL0617 binds to SARS-CoV PLP, abolishes its deubiquitinase activity, and thus inhibits viral replication (Ratia et al., 2008). HCMV UL48 and HSV UL36 execute DUB activity in K63 and K48 ubiquitin linkages. HCMV UL48 C24 mutant with mutations in the active site residues that completely abolish DUB activity results in a notable decrease in HCMV viral protein expression and virus proliferation (Kim et al., 2009). Furthermore, naphthalene inhibitor targeting SARS-CoV2 PLP suppresses the activity of PLP and viral replication by interfering with its deubiquitinating activity (Ratia et al., 2006; Freitas et al., 2020).

\section{CONCLUSION AND PERSPECTIVE}

Deubiquitinases are crucial regulators of viral replication and exert their function in multiple steps of signaling pathways to modulate host innate immune response. Among them, hostencoded DUBs play an indispensable role in PTMs, as they reverse the process of ubiquitination and allow for the finetuning of Ub modification. As key regulators of viral replication, host DUBs have two major functional mechanisms. First, they widely participate in innate immune pathways, deubiquitinate and stabilize critical signaling molecules, thus enhancing the strength of the antiviral immune response. Second, host DUBs interact with viral proteins that are important for replication and affect viral replication positively or negatively. In addition, viruses encode DUBs or protein domains that possess DUB activity.

In most cases, the biological function of viral DUBs is to antagonize the host immune system and ensure its proliferation.

\section{REFERENCES}

Akira, S., Uematsu, S., and Takeuchi, O. (2006). Pathogen recognition and innate immunity. Cell 124, 783-801. doi: 10.1016/j.cell.2006.02.015

Ali, A., Raja, R., Farooqui, S. R., Ahmad, S., and Banerjea, A. C. (2017). USP7 deubiquitinase controls HIV-1 production by stabilizing Tat protein. Biochem. J. 474, 1653-1668. doi: 10.1042/BCJ20160304

Atkins, S. L., Motaib, S., Wiser, L. C., Hopcraft, S. E., Hardy, P. B., Shackelford, J., et al. (2020). Small molecule screening identifies inhibitors of the EpsteinBarr virus deubiquitinating enzyme, BPLF1. Antiviral Res. 173:104649. doi: 10.1016/j.antiviral.2019.104649

Baker, R. T., Tobias, J. W., and Varshavsky, A. (1992). Ubiquitin-specific proteases of Saccharomyces cerevisiae. Cloning of UBP2 and UBP3, and functional analysis of the UBP gene family. J. Biol. Chem. 267, 23364-23375.

Balakirev, M. Y., Jaquinod, M., Haas, A. L., and Chroboczek, J. (2002). Deubiquitinating function of adenovirus proteinase. J. Virol. 76, 6323-6331. doi: 10.1128/jvi.76.12.6323-6331.2002

Barretto, N., Jukneliene, D., Ratia, K., Chen, Z., Mesecar, A. D., and Baker, S. C. (2005). The papain-like protease of severe acute respiratory syndrome coronavirus has deubiquitinating activity. J. Virol. 79, 15189-15198. doi: 10. 1128/JVI.79.24.15189-15198.2005

Bekes, M., van der Heden, van Noort, G. J., Ekkebus, R., Ovaa, H., Huang, T. T., et al. (2016). Recognition of Lys48-Linked Di-ubiquitin and Deubiquitinating Activities of the SARS Coronavirus Papain-like Protease. Mol. Cell 62, 572-585. doi: 10.1016/j.molcel.2016.04.016

Bi, H. L., Zhang, X. L., Zhang, Y. L., Xie, X., Xia, Y. L., Du, J., et al. (2020). The deubiquitinase UCHL1 regulates cardiac hypertrophy by stabilizing epidermal growth factor receptor. Sci. Adv. 6:eaax4826. doi: 10.1126/sciadv.aax4826
Like host DUBs, viral DUBs may also be involved in many steps of innate immune signaling to suppress their function. Moreover, viral DUBs regulate viral replication through a variety of mechanisms. Based on these biological roles, both host and viral DUBs represent potential targets for treating diseases.

For DUB-targeted therapy, more effort is needed to further elucidate the cellular pathways involving DUBs and identify DUB substrates. As only a few viral DUBs have been characterized thus far, we need to explore other viral DUBs that remain largely unknown. Moreover, chemical techniques may be employed to identify novel inhibitors of DUBs, and small-molecule antiviral drugs.

\section{AUTHOR CONTRIBUTIONS}

QZ, WG, and QJ wrote this manuscript. WZ revised this manuscript. All authors contributed to the article and approved the submitted version.

\section{FUNDING}

This work was supported in part by funding from the National key R\&D Program of China (2021YFC2301900 and 2301904); the National Natural Science Foundation of China (81930062 and 81672004 to WZ and 31900457 to WG); the Science and Technology Department of Jilin Province (20190101003JH, 20190201272JC, and 20200201331JC); and the Key Laboratory of Molecular Virology, Jilin Province (20102209).

Bodda, C., Reinert, L. S., Fruhwurth, S., Richardo, T., Sun, C., Zhang, B. C., et al. (2020). HSV1 VP1-2 deubiquitinates STING to block type I interferon expression and promote brain infection. J. Exp. Med. 217:20191422. doi: 10. 1084/jem.20191422

Boutell, C., Canning, M., Orr, A., and Everett, R. D. (2005). Reciprocal activities between herpes simplex virus type 1 regulatory protein ICP0, a ubiquitin E3 ligase, and ubiquitin-specific protease USP7. J. Virol. 79, 12342-12354. doi: 10.1128/JVI.79.19.12342-12354.2005

Cai, J., Chen, H. Y., Peng, S. J., Meng, J. L., Wang, Y., Zhou, Y., et al. (2018). USP7TRIM27 axis negatively modulates antiviral type I IFN signaling. FASEB J. 32, 5238-5249. doi: 10.1096/fj.201700473RR

Charbonneau, M. E., Gonzalez-Hernandez, M. J., Showalter, H. D., Donato, N. J., Wobus, C. E., and O'Riordan, M. X. (2014). Small molecule deubiquitinase inhibitors promote macrophage anti-infective capacity. PLoS One 9:e104096. doi: 10.1371/journal.pone.0104096

Chavoshi, S., Egorova, O., Lacdao, I. K., Farhadi, S., Sheng, Y., and Saridakis, V. (2016). Identification of Kaposi Sarcoma Herpesvirus (KSHV) vIRF1 Protein as a Novel Interaction Partner of Human Deubiquitinase USP7. J. Biol. Chem. 291, 6281-6291. doi: 10.1074/jbc.M115.710632

Chen, R., Zhang, L., Zhong, B., Tan, B., Liu, Y., and Shu, H. B. (2010). The ubiquitin-specific protease 17 is involved in virus-triggered type I IFN signaling. Cell Res. 20, 802-811. doi: 10.1038/cr.2010.41

Chen, X., Chou, C. Y., and Chang, G. G. (2009). Thiopurine analogue inhibitors of severe acute respiratory syndrome-coronavirus papain-like protease, a deubiquitinating and deISGylating enzyme. Antivir. Chem. Chemother. 19, 151-156. doi: 10.1177/095632020901900402

Chen, X., Yang, X., Zheng, Y., Yang, Y., Xing, Y., and Chen, Z. (2014). SARS coronavirus papain-like protease inhibits the type I interferon signaling 
pathway through interaction with the STING-TRAF3-TBK1 complex. Protein Cell 5, 369-381. doi: 10.1007/s13238-014-0026-3

Chow, K. T., Gale, M. Jr., and Loo, Y. M. (2018). RIG-I and Other RNA Sensors in Antiviral Immunity. Annu. Rev. Immunol. 36, 667-694. doi: 10.1146/annurevimmunol-042617-053309

Clague, M. J., Barsukov, I., Coulson, J. M., Liu, H., Rigden, D. J., and Urbé, S. (2013). Deubiquitylases From Genes to Organism. Physiol. Rev. 93, 1289-1315. doi: 10.1152/physrev.00002.2013

Clague, M. J., Urbe, S., and Komander, D. (2019). Breaking the chains: deubiquitylating enzyme specificity begets function. Nat. Rev. Mol. Cell Biol. 20, 338-352. doi: 10.1038/s41580-019-0099-1

Clementz, M. A., Chen, Z., Banach, B. S., Wang, Y., Sun, L., Ratia, K., et al. (2010). Deubiquitinating and interferon antagonism activities of coronavirus papain-like proteases. J. Virol. 84, 4619-4629. doi: 10.1128/JVI.02 406-09

Cui, J., Song, Y., Li, Y., Zhu, Q., Tan, P., Qin, Y., et al. (2014). USP3 inhibits type I interferon signaling by deubiquitinating RIG-I-like receptors. Cell Res. 24, 400-416. doi: 10.1038/cr.2013.170

Czech-Sioli, M., Siebels, S., Radau, S., Zahedi, R. P., Schmidt, C., Dobner, T., et al. (2020). The Ubiquitin-Specific Protease Usp7, a Novel Merkel Cell Polyomavirus Large T-Antigen Interaction Partner, Modulates Viral DNA Replication. J. Virol. 94:19. doi: 10.1128/JVI.01638-19

Daubeuf, S., Singh, D., Tan, Y., Liu, H., Federoff, H. J., Bowers, W. J., et al. (2009). HSV ICP0 recruits USP7 to modulate TLR-mediated innate response. Blood 113, 3264-3275. doi: 10.1182/blood-2008-07-168203

De Nola, R., Menga, A., Castegna, A., Loizzi, V., Ranieri, G., Cicinelli, E., et al. (2019). The Crowded Crosstalk between Cancer Cells and Stromal Microenvironment in Gynecological Malignancies: Biological Pathways and Therapeutic Implication. Int. J. Mol. Sci. 20:ijms20102401. doi: 10.3390/ ijms20102401

Deribe, Y. L., Pawson, T., and Dikic, I. (2010). Post-translational modifications in signal integration. Nat. Struct. Mol. Biol. 17, 666-672. doi: 10.1038/nsmb.1842

Devaraj, S. G., Wang, N., Chen, Z., Chen, Z., Tseng, M., Barretto, N., et al. (2007). Regulation of IRF-3-dependent innate immunity by the papain-like protease domain of the severe acute respiratory syndrome coronavirus. J. Biol. Chem. 282, 32208-32221. doi: 10.1074/jbc.M704870200

Dong, X., Guan, J., Zheng, C., and Zheng, X. (2017). The herpes simplex virus 1 UL36USP deubiquitinase suppresses DNA repair in host cells via deubiquitination of proliferating cell nuclear antigen. J. Biol. Chem. 292, 84728483. doi: $10.1074 /$ jbc.M117.778076

Everett, R. D., Meredith, M., Orr, A., Cross, A., Kathoria, M., and Parkinson, J. (1997). A novel ubiquitin-specific protease is dynamically associated with the PML nuclear domain and binds to a herpesvirus regulatory protein. EMBO J. 16, 1519-1530. doi: 10.1093/emboj/16.7.1519

Fan, Y., Mao, R., Yu, Y., Liu, S., Shi, Z., Cheng, J., et al. (2014). USP21 negatively regulates antiviral response by acting as a RIG-I deubiquitinase. J. Exp. Med. 211, 313-328. doi: 10.1084/jem.20122844

Fieulaine, S., Witte, M. D., Theile, C. S., Ayach, M., Ploegh, H. L., Jupin, I., et al. (2020). Turnip yellow mosaic virus protease binds ubiquitin suboptimally to fine-tune its deubiquitinase activity. J. Biol. Chem295, 13769-13783. doi: 10 1074/jbc.RA120.014628

Freitas, B. T., Durie, I. A., Murray, J., Longo, J. E., Miller, H. C., Crich, D., et al. (2020). Characterization and Noncovalent Inhibition of the Deubiquitinase and deISGylase Activity of SARS-CoV-2 Papain-Like Protease. ACS Infect. Dis. 6, 2099-2109. doi: 10.1021/acsinfecdis.0c00168

Friedman, C. S., O’Donnell, M. A., Legarda-Addison, D., Ng, A., Cardenas, W. B., Yount, J. S., et al. (2008). The tumour suppressor CYLD is a negative regulator of RIG-I-mediated antiviral response. EMBO Rep. 9, 930-936. doi: 10.1038/ embor.2008.136

Frieman, M., Ratia, K., Johnston, R. E., Mesecar, A. D., and Baric, R. S. (2009). Severe acute respiratory syndrome coronavirus papain-like protease ubiquitinlike domain and catalytic domain regulate antagonism of IRF3 and NF-kappaB signaling. J. Virol. 83, 6689-6705. doi: 10.1128/JVI.02220-08

Fuchs, A. C. D., Maldoner, L., Wojtynek, M., Hartmann, M. D., and Martin, J. (2018). Rpn11-mediated ubiquitin processing in an ancestral archaeal ubiquitination system. Nat. Commun. 9:2696. doi: 10.1038/s41467-018-0 5198-1

Gack, M. U., Shin, Y. C., Joo, C. H., Urano, T., Liang, C., Sun, L., et al. (2007). TRIM25 RING-finger E3 ubiquitin ligase is essential for RIG-I-mediated antiviral activity. Nature 446, 916-920. doi: 10.1038/nature05732
Gallardo, C., Soler, A., Rodze, I., Nieto, R., Cano-Gómez, C., FernandezPinero, J., et al. (2019). Attenuated and non-haemadsorbing (non-HAD) genotype II African swine fever virus (ASFV) isolated in Europe, Latvia 2017. Transboundary Emerg. Dis. 66, 1399-1404. doi: 10.1111/tbed.13132

García, L. L., Padilla, L., and Castaño, J. C. (2017). Inhibitors compounds of the flavivirus replication process. Virol. J. 14:95. doi: 10.1186/s12985-017-0761-1

Gonzalez-Hernandez, M. J., Pal, A., Gyan, K. E., Charbonneau, M. E., Showalter, H. D., Donato, N. J., et al. (2014). Chemical derivatives of a small molecule deubiquitinase inhibitor have antiviral activity against several RNA viruses. PLoS One 9:e94491. doi: 10.1371/journal.pone.0094491

$\mathrm{Gu}, \mathrm{Z}$., and Shi, W. (2016). Manipulation of viral infection by deubiquitinating enzymes: new players in host-virus interactions. Future Microbiol. 11, 14351446. doi: $10.2217 / \mathrm{fmb}-2016-0091$

Gu, Z., Shi, W., Zhang, L., Hu, Z., and Xu, C. (2017). USP19 suppresses cellular type I interferon signaling by targeting TRAF3 for deubiquitination. Future Microbiol. 12, 767-779. doi: 10.2217/fmb-2017-0006

Guo, Y., Jiang, F., Kong, L., Li, B., Yang, Y., Zhang, L., et al. (2019). Cutting Edge: USP27X Deubiquitinates and Stabilizes the DNA Sensor cGAS to Regulate Cytosolic DNA-Mediated Signaling. J. Immunol. 203, 2049-2054. doi: 10.4049/ jimmunol.1900514

Guo, Y., Jiang, F., Kong, L., Wu, H., Zhang, H., Chen, X., et al. (2020). OTUD5 promotes innate antiviral and antitumor immunity through deubiquitinating and stabilizing STING. Cell Mol. Immunol. 2020:5. doi: 10.1038/s41423-02000531-5

Gupta, S., Yla-Anttila, P., Sandalova, T., Sun, R., Achour, A., and Masucci, M. G. (2019). 14-3-3 scaffold proteins mediate the inactivation of trim 25 and inhibition of the type I interferon response by herpesvirus deconjugases. PLoS Pathog. 15:e1008146. doi: 10.1371/journal.ppat.1008146

Harrigan, J. A., Jacq, X., Martin, N. M., and Jackson, S. P. (2018). Deubiquitylating enzymes and drug discovery: emerging opportunities. Nat. Rev. Drug Discov. 17, 57-78. doi: $10.1038 / \mathrm{nrd} .2017 .152$

Hermanns, T., and Hofmann, K. (2019). Bacterial DUBs: deubiquitination beyond the seven classes. Biochem. Soc. Transact. 47, 1857-1866. doi: 10.1042/ BST20190526

Hilterbrand, A. T., Boutz, D. R., Marcotte, E. M., and Upton, J. W. (2017). Murine Cytomegalovirus Deubiquitinase Regulates Viral Chemokine Levels To Control Inflammation and Pathogenesis. mBio 8:16. doi: 10.1128/mBio.01864- 16

Holowaty, M. N., and Frappier, L. (2004). HAUSP/USP7 as an Epstein-Barr virus target. Biochem. Soc. Trans. 32(Pt 5), 731-732. doi: 10.1042/BST0320731

Holowaty, M. N., Zeghouf, M., Wu, H., Tellam, J., Athanasopoulos, V., Greenblatt, J., et al. (2003). Protein profiling with Epstein-Barr nuclear antigen-1 reveals an interaction with the herpesvirus-associated ubiquitin-specific protease HAUSP/USP7. J. Biol. Chem. 278, 29987-29994. doi: 10.1074/jbc.M303977200

Hu, X., Tian, J., Kang, H., Guo, D., Liu, J., Liu, D., et al. (2017). Transmissible Gastroenteritis Virus Papain-Like Protease 1 Antagonizes Production of Interferon-beta through Its Deubiquitinase Activity. Biomed. Res. Int. 2017:7089091. doi: 10.1155/2017/7089091

Hu, Y., Bai, X., Zhang, C., Chakrabarti, S., Tang, B., Xiong, H., et al. (2020). Ubiquitination-activating enzymes UBE1 and UBA6 regulate ubiquitination and expression of cardiac sodium channel Nav1.5. Biochem. J. 477, 1683-1700. doi: 10.1042/BCJ20200138

Inn, K. S., Lee, S. H., Rathbun, J. Y., Wong, L. Y., Toth, Z., Machida, K., et al. (2011). Inhibition of RIG-I-mediated signaling by Kaposi's sarcoma-associated herpesvirus-encoded deubiquitinase ORF64. J. Virol. 85, 10899-10904. doi: 10. 1128/JVI.00690-11

Isaacson, M. K., and Ploegh, H. L. (2009). Ubiquitination, ubiquitin-like modifiers, and deubiquitination in viral infection. Cell Host Microbe 5, 559-570. doi: 10.1016/j.chom.2009.05.012

Ivashkiv, L. B., and Donlin, L. T. (2014). Regulation of type I interferon responses. Nat. Rev. Immunol. 14, 36-49. doi: 10.1038/nri3581

Jager, W., Santag, S., Weidner-Glunde, M., Gellermann, E., Kati, S., Pietrek, M., et al. (2012). The ubiquitin-specific protease USP7 modulates the replication of Kaposi's sarcoma-associated herpesvirus latent episomal DNA. J. Virol. 86, 6745-6757. doi: 10.1128/JVI.06840-11

Jarosinski, K., Kattenhorn, L., Kaufer, B., Ploegh, H., and Osterrieder, N. (2007). A herpesvirus ubiquitin-specific protease is critical for efficient $\mathrm{T}$ cell lymphoma formation. Proc. Natl. Acad. Sci. U S A. 104, 20025-20030. doi: 10.1073/pnas. 0706295104

Jia, P., Zhang, W., Xiang, Y., Lu, X., Liu, W., Jia, K., et al. (2020). Ubiquitin-specific protease 5 was involved in the interferon response to RGNNV in sea perch 
(Lateolabrax japonicus). Fish Shellfish Immunol. 103, 239-247. doi: 10.1016/j. fsi.2020.04.065

Jin, Y., Zhao, X., Zhang, Q., Zhang, Y., Fu, X., Hu, X., et al. (2020). Cancerassociated mutation abolishes the impact of TRIM21 on the invasion of breast cancer cells. Int. J. Biol. Macromol. 142, 782-789. doi: 10.1016/j.ijbiomac.2019. 10.019

Kategaya, L., Di Lello, P., Rougé, L., Pastor, R., Clark, K. R., Drummond, J., et al. (2017). USP7 small-molecule inhibitors interfere with ubiquitin binding. Nature 550, 534-538. doi: 10.1038/nature24006

Kattenhorn, L. M., Korbel, G. A., Kessler, B. M., Spooner, E., and Ploegh, H. L. (2005). A deubiquitinating enzyme encoded by HSV-1 belongs to a family of cysteine proteases that is conserved across the family Herpesviridae. Mol. Cell 19, 547-557. doi: 10.1016/j.molcel.2005.07.003

Kawai, T., and Akira, S. (2011). Toll-like receptors and their crosstalk with other innate receptors in infection and immunity. Immunity 34, 637-650. doi: 10 . 1016/j.immuni.2011.05.006

Kayagaki, N., Phung, Q., Chan, S., Chaudhari, R., Quan, C., O’Rourke, K. M., et al. (2007). DUBA: a deubiquitinase that regulates type I interferon production. Science 318, 1628-1632. doi: 10.1126/science.1145918

Kell, A. M., and Gale, M. Jr. (2015). RIG-I in RNA virus recognition. Virology 47, 110-121. doi: 10.1016/j.virol.2015.02.017

Kim, E. T., Oh, S. E., Lee, Y. O., Gibson, W., and Ahn, J. H. (2009). Cleavage specificity of the UL48 deubiquitinating protease activity of human cytomegalovirus and the growth of an active-site mutant virus in cultured cells. J. Virol. 83, 12046-12056. doi: 10.1128/JVI.00411-09

Kiran, S., Dar, A., Singh, S. K., Lee, K. Y., and Dutta, A. (2018). The Deubiquitinase USP46 Is Essential for Proliferation and Tumor Growth of HPV-Transformed Cancers. Mol. Cell 72, 823.e-835.e. doi: 10.1016/j.molcel.2018.09.019

Komander, D., and Rape, M. (2012). The ubiquitin code. Annu. Rev. Biochem. 81, 203-229. doi: 10.1146/annurev-biochem-060310-170328

Kosulin, K., Lam, E., Heim, A., Dobner, T., and Rodriguez, E. (2018). Broadspectrum antiviral activity of the deubiquitinase inhibitor HBX against human adenoviruses. Antivir. Ther. 23, 475-483. doi: 10.3851/IMP3230

Kovalenko, A., Chable-Bessia, C., Cantarella, G., Israel, A., Wallach, D., and Courtois, G. (2003). The tumour suppressor CYLD negatively regulates NFkappaB signalling by deubiquitination. Nature 424, 801-805. doi: 10.1038/ nature 01802

Kumar, R., Khandelwal, N., Thachamvally, R., Tripathi, B. N., Barua, S., Kashyap, S. K., et al. (2018). Role of MAPK/MNK1 signaling in virus replication. Virus Res. 253, 48-61. doi: 10.1016/j.virusres.2018.05.028

Kumari, P., and Kumar, H. (2018). Viral deubiquitinases: role in evasion of anti-viral innate immunity. Crit. Rev. Microbiol. 44, 304-317. doi: 10.1080/ 1040841X.2017.1368999

Kumari, P., Saha, I., Narayanan, A., Narayanan, S., Takaoka, A., Kumar, N. S., et al. (2017). Essential role of HCMV deubiquitinase in promoting oncogenesis by targeting anti-viral innate immune signaling pathways. Cell Death Dis. 8:e3078. doi: $10.1038 /$ cddis. 2017.461

Kwon, K. M., Oh, S. E., Kim, Y. E., Han, T. H., and Ahn, J. H. (2017). Cooperative inhibition of RIP1-mediated NF-kappaB signaling by cytomegalovirus-encoded deubiquitinase and inactive homolog of cellular ribonucleotide reductase large subunit. PLoS Pathog. 13:e1006423. doi: 10.1371/journal.ppat.1006423

Lehoux, M., Gagnon, D., and Archambault, J. (2014). E1-mediated recruitment of a UAF1-USP deubiquitinase complex facilitates human papillomavirus DNA replication. J. Virol. 88, 8545-8555. doi: 10.1128/JVI.00379-14

Li, H., Li, J., Zhai, Y., Zhang, L., Cui, P., Feng, L., et al. (2020). Gga-miR-30d regulates infectious bronchitis virus infection by targeting USP47 in HD11 cells. Microb. Pathog. 141:103998. doi: 10.1016/j.micpath.2020.103998

Li, R., Ahmad, I., Li, S., Johnson, S., Liangliang, S., and Zheng, Y.-H. (2021). Cul3-KLHL20 E3 ubiquitin ligase plays a key role in the arms race between HIV-1 and host restriction. Res. Square 2021:v1. doi: 10.21203/rs.3.rs-912 958/v1

Li, S. W., Wang, C. Y., Jou, Y. J., Huang, S. H., Hsiao, L. H., Wan, L., et al. (2016). SARS Coronavirus Papain-Like Protease Inhibits the TLR7 Signaling Pathway through Removing Lys63-Linked Polyubiquitination of TRAF3 and TRAF6. Int. J. Mol. Sci. 17:ijms17050678. doi: 10.3390/ijms17050678

Li, S., Zheng, H., Mao, A. P., Zhong, B., Li, Y., Liu, Y., et al. (2010). Regulation of virus-triggered signaling by OTUB1- and OTUB2-mediated deubiquitination of TRAF3 and TRAF6. J. Biol. Chem. 285, 4291-4297. doi: 10.1074/jbc.M109. 074971
Liao, T. L., Wu, C. Y., Su, W. C., Jeng, K. S., and Lai, M. M. (2010). Ubiquitination and deubiquitination of NP protein regulates influenza A virus RNA replication. EMBO J. 29, 3879-3890. doi: 10.1038/emboj.2010.250

Lim, K. H., and Staudt, L. M. (2013). Toll-like receptor signaling. Cold Spring Harb. Perspect. Biol. 5:a011247. doi: 10.1101/cshperspect.a011247

Lin, R., Yang, L., Nakhaei, P., Sun, Q., Sharif-Askari, E., Julkunen, I., et al. (2006). Negative regulation of the retinoic acid-inducible gene I-induced antiviral state by the ubiquitin-editing protein A20. J. Biol. Chem. 281, 2095-2103. doi: 10. 1074/jbc.M510326200

Lindner, H. A., Fotouhi-Ardakani, N., Lytvyn, V., Lachance, P., Sulea, T., and Menard, R. (2005). The papain-like protease from the severe acute respiratory syndrome coronavirus is a deubiquitinating enzyme. J. Virol. 79, 15199-15208. doi: 10.1128/JVI.79.24.15199-15208.2005

Liu, J., Jin, L., Chen, X., Yuan, Y., Zuo, Y., Miao, Y., et al. (2020). USP12 translocation maintains interferon antiviral efficacy by inhibiting CBP acetyltransferase activity. PLoS Pathog. 16:e1008215. doi: 10.1371/journal.ppat. 1008215

Liu, N., Chai, R., Liu, B., Zhang, Z., Zhang, S., Zhang, J., et al. (2016). Ubiquitinspecific protease 14 regulates cardiac hypertrophy progression by increasing GSK-3 $\beta$ phosphorylation. Biochem. Biophys. Res. Commun. 478, 1236-1241. doi: 10.1016/j.bbrc.2016.08.100

Liuyu, T., Yu, K., Ye, L., Zhang, Z., Zhang, M., Ren, Y., et al. (2019). Induction of OTUD4 by viral infection promotes antiviral responses through deubiquitinating and stabilizing MAVS. Cell Res. 29, 67-79. doi: 10.1038/ s41422-018-0107-6

Luo, Q., Zhang, L., Wei, F., Fang, Q., Bao, F., Mi, S., et al. (2018). mTORC1 Negatively Regulates the Replication of Classical Swine Fever Virus Through Autophagy and IRES-Dependent Translation. iScience 3, 87-101. doi: 10.1016/ j.isci.2018.04.010

Medina, G. N., Azzinaro, P., Ramirez-Medina, E., Gutkoska, J., Fang, Y., Diaz-San Segundo, F., et al. (2020). Impairment of the DeISGylation Activity of Foot-andMouth Disease Virus Lpro Causes Attenuation In Vitro and In Vivo. J. Virol. 94:20. doi: 10.1128/JVI.00341-20

Mennerich, D., Kubaichuk, K., and Kietzmann, T. (2019). DUBs, Hypoxia, and Cancer. Trends Cancer 5, 632-653. doi: 10.1016/j.trecan.2019.08.005

Mevissen, T. E. T., and Komander, D. (2017). Mechanisms of Deubiquitinase Specificity and Regulation. Annu. Rev. Biochem. 86, 159-192. doi: 10.1146/ annurev-biochem-061516-044916

Nag, D. K., and Finley, D. (2012). A small-molecule inhibitor of deubiquitinating enzyme USP14 inhibits Dengue virus replication. Virus Res. 165, 103-106. doi: 10.1016/j.virusres.2012.01.009

Nan, Y., Yu, Y., Ma, Z., Khattar, S. K., Fredericksen, B., and Zhang, Y. J. (2014). Hepatitis E virus inhibits type I interferon induction by ORF1 products. J. Virol. 88, 11924-11932. doi: 10.1128/JVI.01935-14

Nicholson, B., and Suresh Kumar, K. G. (2011). The multifaceted roles of USP7: new therapeutic opportunities. Cell Biochem. Biophys. 60, 61-68. doi: 10.1007/ s12013-011-9185-5

Okamoto, M., Kouwaki, T., Fukushima, Y., and Oshiumi, H. (2017). Regulation of RIG-I Activation by K63-Linked Polyubiquitination. Front. Immunol. 8:1942. doi: 10.3389/fimmu.2017.01942

Oshiumi, H., Miyashita, M., Matsumoto, M., and Seya, T. (2013). A distinct role of Riplet-mediated K63-Linked polyubiquitination of the RIG-I repressor domain in human antiviral innate immune responses. PLoS Pathog. 9:e1003533. doi: 10.1371/journal.ppat.1003533

Papa, F. R., and Hochstrasser, M. (1993). The yeast DOA4 gene encodes a deubiquitinating enzyme related to a product of the human tre- 2 oncogene. Nature 366, 313-319. doi: 10.1038/366313a0

Passalacqua, K. D., Charbonneau, M. E., Donato, N. J., Showalter, H. D., Sun, D., Wen, B., et al. (2016). Anti-infective Activity of 2-Cyano-3-Acrylamide Inhibitors with Improved Drug-Like Properties against Two Intracellular Pathogens. Antimicrob. Agents Chemother. 60, 4183-4196. doi: 10.1128/AAC. 03021-15

Pauli, E. K., Chan, Y. K., Davis, M. E., Gableske, S., Wang, M. K., Feister, K. F., et al. (2014). The ubiquitin-specific protease USP15 promotes RIG-I-mediated antiviral signaling by deubiquitylating TRIM25. Sci. Signal 7:ra3. doi: 10.1126/ scisignal.2004577

Peng, Y., Guo, J., Sun, T., Fu, Y., Zheng, H., Dong, C., et al. (2020). USP39 Serves as a Deubiquitinase to Stabilize STAT1 and Sustains Type I IFN-Induced Antiviral Immunity. J. Immunol. 205, 3167-3178. doi: 10.4049/jimmunol.1901384 
Perry, J. W., Ahmed, M., Chang, K. O., Donato, N. J., Showalter, H. D., and Wobus, C. E. (2012). Antiviral activity of a small molecule deubiquitinase inhibitor occurs via induction of the unfolded protein response. PLoS Pathog. 8:e1002783. doi: 10.1371/journal.ppat.1002783

Pyeon, D., Timani, K. A., Gulraiz, F., He, J. J., and Park, I. W. (2016). Function of ubiquitin (Ub) specific protease 15 (USP15) in HIV-1 replication and viral protein degradation. Virus Res. 223, 161-169. doi: 10.1016/j.virusres.2016. 07.009

Qi, L., Zang, H., Wu, W., Nagarkatti, P., Nagarkatti, M., Liu, Q., et al. (2020). CYLD exaggerates pressure overload-induced cardiomyopathy via suppressing autolysosome efflux in cardiomyocytes. J. Mol. Cell Cardiol. 145, 59-73. doi: 10.1016/j.yjmcc.2020.06.004

Qian, L., Zuo, Y., Deng, W., Miao, Y., Liu, J., Yuan, Y., et al. (2018). MCPIP1 is a positive regulator of type I interferons antiviral activity. Biochem. Biophys. Res. Commun. 498, 891-897. doi: 10.1016/j.bbrc.2018.03.076

Ratia, K., Pegan, S., Takayama, J., Sleeman, K., Coughlin, M., Baliji, S., et al. (2008). A noncovalent class of papain-like protease/deubiquitinase inhibitors blocks SARS virus replication. Proc. Natl. Acad. Sci. U S A. 105, 16119-16124. doi: 10.1073/pnas.0805240105

Ratia, K., Saikatendu, K. S., Santarsiero, B. D., Barretto, N., Baker, S. C., Stevens, R. C., et al. (2006). Severe acute respiratory syndrome coronavirus papain-like protease: structure of a viral deubiquitinating enzyme. Proc. Natl. Acad. Sci. US A. 103, 5717-5722. doi: 10.1073/pnas.0510851103

Ren, Y., Zhao, P., Liu, J., Yuan, Y., Cheng, Q., Zuo, Y., et al. (2016). Deubiquitinase USP2a Sustains Interferons Antiviral Activity by Restricting Ubiquitination of Activated STAT1 in the Nucleus. PLoS Pathog. 12:e1005764. doi: 10.1371/ journal.ppat.1005764

Sacco, J. J., Coulson, J. M., Clague, M. J., and Urbe, S. (2010). Emerging roles of deubiquitinases in cancer-associated pathways. IUBMB Life 62, 140-157. doi: 10.1002/iub.300

Saito, S., Murata, T., Kanda, T., Isomura, H., Narita, Y., Sugimoto, A., et al. (2013). Epstein-Barr virus deubiquitinase downregulates TRAF6-mediated NF-kappaB signaling during productive replication. J. Virol. 87, 4060-4070. doi: 10.1128/ JVI.02020-12

Sarkari, F., Sanchez-Alcaraz, T., Wang, S., Holowaty, M. N., Sheng, Y., and Frappier, L. (2009). EBNA1-mediated recruitment of a histone H2B deubiquitylating complex to the Epstein-Barr virus latent origin of DNA replication. PLoS Pathog. 5:e1000624. doi: 10.1371/journal.ppat.1000624

Saxena, N., and Kumar, V. (2014). The HBx oncoprotein of hepatitis B virus deregulates the cell cycle by promoting the intracellular accumulation and re-compartmentalization of the cellular deubiquitinase USP37. PLoS One 9:e111256. doi: 10.1371/journal.pone.0111256

Scholte, F. E. M., Hua, B. L., Spengler, J. R., Dzimianski, J. V., Coleman-McCray, J. D., Welch, S. R., et al. (2019). Stable Occupancy of the Crimean-Congo Hemorrhagic Fever Virus-Encoded Deubiquitinase Blocks Viral Infection. mBio 10:19. doi: 10.1128/mBio.01065-19

Scholte, F. E. M., Zivcec, M., Dzimianski, J. V., Deaton, M. K., Spengler, J. R., Welch, S. R., et al. (2017). Crimean-Congo Hemorrhagic Fever Virus Suppresses Innate Immune Responses via a Ubiquitin and ISG15 Specific Protease. Cell Rep. 20, 2396-2407. doi: 10.1016/j.celrep.2017.08.040

Seo, J. H., Agarwal, E., Bryant, K. G., Caino, M. C., Kim, E. T., Kossenkov, A. V., et al. (2018). Syntaphilin Ubiquitination Regulates Mitochondrial Dynamics and Tumor Cell Movements. Cancer Res. 78:4215. doi: 10.1158/0008-5472. CAN-18-0595

Setz, C., Friedrich, M., Rauch, P., Fraedrich, K., Matthaei, A., Traxdorf, M., et al. (2017). Inhibitors of Deubiquitinating Enzymes Block HIV-1 Replication and Augment the Presentation of Gag-Derived MHC-I Epitopes. Viruses 9:v9080222. doi: 10.3390/v9080222

Shembade, N., Ma, A., and Harhaj, E. W. (2010). Inhibition of NF-kappaB signaling by A20 through disruption of ubiquitin enzyme complexes. Science 327, 11351139. doi: 10.1126/science. 1182364

Shin, D., Mukherjee, R., Grewe, D., Bojkova, D., Baek, K., Bhattacharya, A., et al. (2020). Papain-like protease regulates SARS-CoV-2 viral spread and innate immunity. Nature 587, 657-662. doi: 10.1038/s41586-020-2601-5

Song, G., Liu, B., Li, Z., Wu, H., Wang, P., Zhao, K., et al. (2016). E3 ubiquitin ligase RNF128 promotes innate antiviral immunity through K63linked ubiquitination of TBK1. Nat. Immunol. 17, 1342-1351. doi: 10.1038/ni. 3588

Su, Y., Shi, P., Zhang, L., Lu, D., Zhao, C., Li, R., et al. (2018). The Superimposed Deubiquitination Effect of OTULIN and Porcine Reproductive and Respiratory
Syndrome Virus (PRRSV) Nsp11 Promotes Multiplication of PRRSV. J. Virol. 92:18. doi: 10.1128/JVI.00175-18

Sun, C., Schattgen, S. A., Pisitkun, P., Jorgensen, J. P., Hilterbrand, A. T., Wang, L. J., et al. (2015). Evasion of innate cytosolic DNA sensing by a gammaherpesvirus facilitates establishment of latent infection. J. Immunol. 194, 1819-1831. doi: 10.4049/jimmunol.1402495

Sun, H., Zhang, Q., Jing, Y. Y., Zhang, M., Wang, H. Y., Cai, Z., et al. (2017). USP13 negatively regulates antiviral responses by deubiquitinating STING. Nat. Commun. 8:15534. doi: 10.1038/ncomms15534

Sun, L., Xing, Y., Chen, X., Zheng, Y., Yang, Y., Nichols, D. B., et al. (2012). Coronavirus papain-like proteases negatively regulate antiviral innate immune response through disruption of STING-mediated signaling. PLoS One 7:e30802. doi: 10.1371/journal.pone.0030802

Sun, Z., Chen, Z., Lawson, S. R., and Fang, Y. (2010). The cysteine protease domain of porcine reproductive and respiratory syndrome virus nonstructural protein 2 possesses deubiquitinating and interferon antagonism functions. J. Virol. 84, 7832-7846. doi: 10.1128/JVI.00217-10

Tanaka, Y., and Chen, Z. J. (2012). STING specifies IRF3 phosphorylation by TBK1 in the cytosolic DNA signaling pathway. Sci. Signal 5:ra20. doi: 10.1126/ scisignal.2002521

Tang, Y., Joo, D., Liu, G., Tu, H., You, J., Jin, J., et al. (2018). Linear ubiquitination of cFLIP induced by LUBAC contributes to TNF $\alpha$-induced apoptosis. J. Biol. Chem. 293, 20062-20072. doi: 10.1074/jbc.RA118.005449

Tanuma, J., Lee, K. H., Haneuse, S., Matsumoto, S., Nguyen, D. T., Nguyen, D. T., et al. (2016). Incidence of AIDS-Defining Opportunistic Infections and Mortality during Antiretroviral Therapy in a Cohort of Adult HIV-Infected Individuals in Hanoi, 2007-2014. PLoS One 11:e0150781. doi: 10.1371/journal. pone. 0150781

Tchesnokov, E. P., Bailey-Elkin, B. A., Mark, B. L., and Gotte, M. (2020). Independent inhibition of the polymerase and deubiquitinase activities of the Crimean-Congo Hemorrhagic Fever Virus full-length L-protein. PLoS Negl. Trop. Dis. 14:e0008283. doi: 10.1371/journal.pntd.0008283

Thomas, D. L. (2019). Global Elimination of Chronic Hepatitis. New Engl. J. Med. 380, 2041-2050. doi: 10.1056/NEJMra1810477

Tobias, J. W., and Varshavsky, A. (1991). Cloning and functional analysis of the ubiquitin-specific protease gene UBP1 of Saccharomyces cerevisiae. J. Biol. Chem. 266, 12021-12028. doi: 10.1016/s0021-9258(18)99059-9

Trompouki, E., Hatzivassiliou, E., Tsichritzis, T., Farmer, H., Ashworth, A., and Mosialos, G. (2003). CYLD is a deubiquitinating enzyme that negatively regulates NF-kappaB activation by TNFR family members. Nature 424, 793796. doi: $10.1038 /$ nature 01803

van Gent, M., Braem, S. G., de Jong, A., Delagic, N., Peeters, J. G., Boer, I. G., et al. (2014). Epstein-Barr virus large tegument protein BPLF1 contributes to innate immune evasion through interference with toll-like receptor signaling. PLoS Pathog. 10:e1003960. doi: 10.1371/journal.ppat.1003960

van Kasteren, P. B., Bailey-Elkin, B. A., James, T. W., Ninaber, D. K., Beugeling, C., Khajehpour, M., et al. (2013). Deubiquitinase function of arterivirus papain-like protease 2 suppresses the innate immune response in infected host cells. Proc. Natl. Acad. Sci. U S A. 110, E838-E847. doi: 10.1073/pnas. 1218464110

van Kasteren, P. B., Beugeling, C., Ninaber, D. K., Frias-Staheli, N., van Boheemen, S., Garcia-Sastre, A., et al. (2012). Arterivirus and nairovirus ovarian tumor domain-containing Deubiquitinases target activated RIG-I to control innate immune signaling. J. Virol. 86, 773-785. doi: 10.1128/JVI.06277-11

Wang, D., Fang, L., Li, P., Sun, L., Fan, J., Zhang, Q., et al. (2011). The leader proteinase of foot-and-mouth disease virus negatively regulates the type I interferon pathway by acting as a viral deubiquitinase. J. Virol. 85, 3758-3766. doi: 10.1128/JVI.02589-10

Wang, G., Chen, G., Zheng, D., Cheng, G., and Tang, H. (2011). PLP2 of mouse hepatitis virus A59 (MHV-A59) targets TBK1 to negatively regulate cellular type I interferon signaling pathway. PLoS One 6:e17192. doi: 10.1371/journal.pone. 0017192

Wang, H., Lai, Y., Mathis, B. J., Wang, W., Li, S., Qu, C., et al. (2015). Deubiquitinating enzyme CYLD mediates pressure overload-induced cardiac maladaptive remodeling and dysfunction via downregulating Nrf2. J. Mol. Cell Cardiol. 84, 143-153. doi: 10.1016/j.yjmcc.2015.04.012

Wang, J., Loveland, A. N., Kattenhorn, L. M., Ploegh, H. L., and Gibson, W. (2006). High-molecular-weight protein (pUL48) of human cytomegalovirus is a competent deubiquitinating protease: mutant viruses altered in its activesite cysteine or histidine are viable. J. Virol. 80, 6003-6012. doi: 10.1128/JVI.00 401-06 
Wang, L., and Dent, S. Y. (2014). Functions of SAGA in development and disease. Epigenomics 6, 329-339. doi: 10.2217/epi.14.22

Wang, L., Zhao, W., Zhang, M., Wang, P., Zhao, K., Zhao, X., et al. (2013). USP4 positively regulates RIG-I-mediated antiviral response through deubiquitination and stabilization of RIG-I. J. Virol. 87, 4507-4515. doi: 10. 1128/JVI.00031-13

Wang, S., Wang, K., Li, J., and Zheng, C. (2013). Herpes simplex virus 1 ubiquitinspecific protease UL36 inhibits beta interferon production by deubiquitinating TRAF3. J. Virol. 87, 11851-11860. doi: 10.1128/JVI.01211-13

Wang, Y. Y., Li, L., Han, K. J., Zhai, Z., and Shu, H. B. (2004). A20 is a potent inhibitor of TLR3- and Sendai virus-induced activation of NF-kappaB and ISRE and IFN-beta promoter. FEBS Lett. 576, 86-90. doi: 10.1016/j.febslet.2004. 08.071

Wertz, I. E., O’Rourke, K. M., Zhou, H., Eby, M., Aravind, L., Seshagiri, S., et al. (2004). De-ubiquitination and ubiquitin ligase domains of A20 downregulate NF-kappaB signalling. Nature 430, 694-699. doi: 10.1038/nature02794

Whitehurst, C. B., Ning, S., Bentz, G. L., Dufour, F., Gershburg, E., Shackelford, J., et al. (2009). The Epstein-Barr virus (EBV) deubiquitinating enzyme BPLF1 reduces EBV ribonucleotide reductase activity. J. Virol. 83, 4345-4353. doi: 10.1128/JVI.02195-08

Whitehurst, C. B., Vaziri, C., Shackelford, J., and Pagano, J. S. (2012). Epstein-Barr virus BPLF1 deubiquitinates PCNA and attenuates polymerase eta recruitment to DNA damage sites. J. Virol. 86, 8097-8106. doi: 10.1128/JVI.00588-12

Wilkinson, K. D. (1997). Regulation of ubiquitin-dependent processes by deubiquitinating enzymes. FASEB J. 11, 1245-1256. doi: 10.1096/fasebj.11.14. 9409543

Wu, C., Shi, B., Yang, D., Zhang, K., Li, J., Wang, J., et al. (2020). Porcine Reproductive and Respiratory Syndrome Virus Promotes SLA-DR-Mediated Antigen Presentation of Nonstructural Proteins To Evoke a Nonneutralizing Antibody Response \&1t;em\&gt;In Vivo\&1t;/em\&gt. J. Virol. 94, e1423-e1420. doi: 10.1128/JVI.01423-20

Xiao, Z., Chang, L., Kim, J., Zhang, P., Hang, Q., Yap, S., et al. (2019). USP37 is a SNAI1 deubiquitinase. Am. J. Cancer Res. 9, 2749-2759.

Xing, Y., Chen, J., Tu, J., Zhang, B., Chen, X., Shi, H., et al. (2013). The papainlike protease of porcine epidemic diarrhea virus negatively regulates type I interferon pathway by acting as a viral deubiquitinase. J. Gen. Virol. 94(Pt 7), 1554-1567. doi: 10.1099/vir.0.051169-0

Xue, Q., Liu, H., Zhu, Z., Yang, F., Xue, Q., Cai, X., et al. (2018). Seneca Valley Virus $3 \mathrm{C}$ protease negatively regulates the type I interferon pathway by acting as a viral deubiquitinase. Antiviral Res. 160, 183-189. doi: 10.1016/j.antiviral. 2018.10.028

Yamamoto, V., Bolanos, J. F., Fiallos, J., Strand, S. E., Morris, K., Shahrokhinia, S., et al. (2020). COVID-19: Review of a 21st Century Pandemic from Etiology to Neuro-psychiatric Implications. J. Alzheimer's Dis. 77, 459-504. doi: 10.3233/ JAD-200831

Yang, W.-L., Jin, G., Li, C.-F., Jeong, Y. S., Moten, A., Xu, D., et al. (2013). Cycles of Ubiquitination and Deubiquitination Critically Regulate Growth FactorMediated Activation of Akt Signaling. Sci. Signal. 6:ra3. doi: 10.1126/scisignal. 2003197

Yang, X., Chen, X., Bian, G., Tu, J., Xing, Y., Wang, Y., et al. (2014). Proteolytic processing, deubiquitinase and interferon antagonist activities of Middle East respiratory syndrome coronavirus papain-like protease. J. Gen. Virol. 95(Pt 3), 614-626. doi: 10.1099/vir.0.059014-0

Ye, L., Zhang, Q., Liuyu, T., Xu, Z., Zhang, M. X., Luo, M. H., et al. (2019). USP49 negatively regulates cellular antiviral responses via deconjugating K63-linked ubiquitination of MITA. PLoS Pathog. 15:e1007680. doi: 10.1371/journal.ppat. 1007680

Ye, R., Su, C., Xu, H., and Zheng, C. (2017). Herpes Simplex Virus 1 UbiquitinSpecific Protease UL36 Abrogates NF-kappaB Activation in DNA Sensing Signal Pathway. J. Virol. 91:16. doi: 10.1128/JVI.02417-16

Yu, Z., Song, H., Jia, M., Zhang, J., Wang, W., Li, Q., et al. (2017). USP1-UAF1 deubiquitinase complex stabilizes TBK1 and enhances antiviral responses. J. Exp. Med. 214, 3553-3563. doi: 10.1084/jem.20170180

Yuan, H., You, J., You, H., and Zheng, C. (2018). Herpes Simplex Virus 1 UL36USP Antagonizes Type I Interferon-Mediated Antiviral Innate Immunity. J. Virol. 92:18. doi: 10.1128/JVI.01161-18

Yuan, L., Chen, Z., Song, S., Wang, S., Tian, C., Xing, G., et al. (2015). p53 degradation by a coronavirus papain-like protease suppresses type I interferon signaling. J. Biol. Chem. 290, 3172-3182. doi: 10.1074/jbc.M114.619890
Yuan, T., Yan, F., Ying, M., Cao, J., He, Q., Zhu, H., et al. (2018). Inhibition of Ubiquitin-Specific Proteases as a Novel Anticancer Therapeutic Strategy. Front. Pharmacol. 9:1080. doi: 10.3389/fphar.2018.01080

Zhang, H., Wang, D., Zhong, H., Luo, R., Shang, M., Liu, D., et al. (2015). Ubiquitin-specific Protease 15 Negatively Regulates Virus-induced Type I Interferon Signaling via Catalytically-dependent and -independent Mechanisms. Sci. Rep. 5:11220. doi: 10.1038/srep11220

Zhang, L., Wei, N., Cui, Y., Hong, Z., Liu, X., Wang, Q., et al. (2018b). The deubiquitinase CYLD is a specific checkpoint of the STING antiviral signaling pathway. PLoS Pathog. 14:e1007435. doi: 10.1371/journal.ppat.1007435

Zhang, L., Liu, J., Qian, L., Feng, Q., Wang, X., Yuan, Y., et al. (2018a). Induction of OTUD1 by RNA viruses potently inhibits innate immune responses by promoting degradation of the MAVS/TRAF3/TRAF6 signalosome. PLoS Pathog. 14:e1007067. doi: 10.1371/journal.ppat.1007067

Zhang, L., Zhao, X., Zhang, M., Zhao, W., and Gao, C. (2014). Ubiquitin-specific protease $2 \mathrm{~b}$ negatively regulates IFN-beta production and antiviral activity by targeting TANK-binding kinase 1. J. Immunol. 193, 2230-2237. doi: 10.4049/ jimmunol.1302634

Zhang, M., Lee, A. J., Wu, X., and Sun, S. C. (2011). Regulation of antiviral innate immunity by deubiquitinase CYLD. Cell Mol. Immunol. 8, 502-504. doi: $10.1038 / \mathrm{cmi} .2011 .42$

Zhang, M., Wu, X., Lee, A. J., Jin, W., Chang, M., Wright, A., et al. (2008). Regulation of IkappaB kinase-related kinases and antiviral responses by tumor suppressor CYLD. J. Biol. Chem. 283, 18621-18626. doi: 10.1074/jbc. M801451200

Zhang, M., Zhang, M. X., Zhang, Q., Zhu, G. F., Yuan, L., Zhang, D. E., et al. (2016). USP18 recruits USP20 to promote innate antiviral response through deubiquitinating STING/MITA. Cell Res. 26, 1302-1319. doi: 10.1038/cr.20 16.125

Zhang, Z., Fang, X., Wu, X., Ling, L., Chu, F., Li, J., et al. (2020). AcetylationDependent Deubiquitinase OTUD3 Controls MAVS Activation in Innate Antiviral Immunity. Mol. Cell 79:e307. doi: 10.1016/j.molcel.2020.06.020

Zheng, D., Chen, G., Guo, B., Cheng, G., and Tang, H. (2008). PLP2, a potent deubiquitinase from murine hepatitis virus, strongly inhibits cellular type I interferon production. Cell Res. 18, 1105-1113. doi: 10.1038/cr.2008.294

Zheng, N., and Shabek, N. (2017). Ubiquitin Ligases: Structure, Function, and Regulation. Annu. Rev. Biochem. 86, 129-157. doi: 10.1146/annurev-biochem060815-014922

Zheng, Y., and Gao, C. (2020). Fine-tuning of antiviral innate immunity by ubiquitination. Adv. Immunol. 145, 95-128. doi: 10.1016/bs.ai.2019.11.004

Zhong, B., Liu, X., Wang, X., Liu, X., Li, H., Darnay, B. G., et al. (2013). Ubiquitinspecific protease 25 regulates TLR4-dependent innate immune responses through deubiquitination of the adaptor protein TRAF3. Sci. Signal. 6:ra35. doi: 10.1126/scisignal.2003708

Zhou, S., Ge, X., Kong, C., Liu, T., Liu, A., Gao, P., et al. (2019). Characterizing the PRRSV nsp2 Deubiquitinase Reveals Dispensability of Cis-Activity for Replication and a Link of nsp2 to Inflammation Induction. Viruses 11:v11100896. doi: 10.3390/v11100896

Zhu, Z., Li, W., Zhang, X., Wang, C., Gao, L., Yang, F., et al. (2020). Footand-Mouth Disease Virus Capsid Protein VP1 Interacts with Host Ribosomal Protein SA To Maintain Activation of the MAPK Signal Pathway and Promote Virus Replication. J. Virol. 94, e1350-e1319. doi: 10.1128/JVI.01350-19

Conflict of Interest: The authors declare that the research was conducted in the absence of any commercial or financial relationships that could be construed as a potential conflict of interest.

Publisher's Note: All claims expressed in this article are solely those of the authors and do not necessarily represent those of their affiliated organizations, or those of the publisher, the editors and the reviewers. Any product that may be evaluated in this article, or claim that may be made by its manufacturer, is not guaranteed or endorsed by the publisher.

Copyright (C) 2022 Zhang, Jia, Gao and Zhang. This is an open-access article distributed under the terms of the Creative Commons Attribution License (CC BY). The use, distribution or reproduction in other forums is permitted, provided the original author(s) and the copyright owner(s) are credited and that the original publication in this journal is cited, in accordance with accepted academic practice. No use, distribution or reproduction is permitted which does not comply with these terms. 